\title{
Dopamine modulates attentional control of auditory perception: DARPP-32 (PPP1R1B) genotype effects on behavior and cortical evoked potentials ${ }^{\text {th }}$
}

\author{
Shu-Chen $\mathrm{Li}^{\mathrm{a}, \mathrm{a}, *, 1,}$, Susanne Passow ${ }^{\mathrm{a}, \mathrm{c}, 1}$, Wilfried Nietfeld $^{\mathrm{d}}$, Julia Schröder ${ }^{\mathrm{d}}$, Lars Bertram ${ }^{\mathrm{d}}$, \\ Hauke R. Heekeren ${ }^{\mathrm{e}}$, Ulman Lindenberger ${ }^{\mathrm{a}}$ \\ ${ }^{a}$ Center for Lifespan Psychology, Max Planck Institute for Human Development, Lentzeallee 94, D-14195 Berlin, Germany \\ ${ }^{\mathrm{b}}$ Department of Psychology, Lifespan Developmental Neuroscience, TU Dresden, Zellescher Weg 17, D-01062 Dresden, Germany \\ ${ }^{\mathrm{c}}$ Department of Biological and Medical Psychology, University of Bergen, Jonas Lies vei 91, N-5009 Bergen, Norway \\ d Department for Vertebrate Genomics, Max Planck Institute for Molecular Genetics, Ihnestrasse 63-73, D-14195 Berlin, Germany \\ e Department of Psychology and Educational Science, Freie Universität Berlin, Habelschwerdter Allee 45, D-14195 Berlin, Germany
}

\section{A R T I C L E I N F O}

\section{Article history:}

Received 23 November 2012

Received in revised form

16 March 2013

Accepted 16 April 2013

Available online 29 April 2013

Keywords:

Attention

Selective attention

Conflict monitoring

Auditory processing

Dopamine

Evoked potentials

DARPP-32

PPP1R1B

\begin{abstract}
A B S T R A C T
Using a specific variant of the dichotic listening paradigm, we studied the influence of dopamine on attentional modulation of auditory perception by assessing effects of allelic variation of a single-nucleotide polymorphism (SNP) rs907094 in the DARPP-32 gene (dopamine and adenosine 3', 5'-monophosphateregulated phosphoprotein 32 kilodations; also known as PPP1R1B) on behavior and cortical evoked potentials. A frequent DARPP-32 haplotype that includes the A allele of this SNP is associated with higher mRNA expression of DARPP-32 protein isoforms, striatal dopamine receptor function, and frontal-striatal connectivity. As we hypothesized, behaviorally the A homozygotes were more flexible in selectively attending to auditory inputs than any G carriers. Moreover, this genotype also affected auditory evoked cortical potentials that reflect early sensory and late attentional processes. Specifically, analyses of eventrelated potentials (ERPs) revealed that amplitudes of an early component of sensory selection (N1) and a late component (N450) reflecting attentional deployment for conflict resolution were larger in A homozygotes than in any G carriers. Taken together, our data lend support for dopamine's role in modulating auditory attention both during the early sensory selection and late conflict resolution stages. (c) 2013 Elsevier Ltd. All rights reserved.
\end{abstract}

\section{Introduction}

Research on neuromodulation of cortical functions indicates that dopaminergic systems are critically involved in working memory and attentional control (for reviews, see Arnsten \& Pilszka, 2011; Seamans \& Yang, 2004). Most studies on dopamine

\footnotetext{
This study was conducted in the Neuromodulation of Lifespan Cognition Project at the Center for Lifespan Psychology, Max Planck Institute for Human Development. Shu-Chen Li's research was also funded by the German Science Foundation (DFG FOR 778). This study was also funded in part through a Ph.D. Fellowship granted to Susanne Passow by the Max Planck International Research Network on Aging (MaxNetAging). Special thanks go to the student assistants for their valuable support during data collection and to all the participants.

* Corresponding author at: Department of Psychology, Lifespan Developmental Neuroscience, TU Dresden, Zellescher Weg 17, D-01062 Dresden, Germany. Tel.: +49351 46334162; fax: +4935146342194.

E-mail addresses: Shu-Chen.Li@tu-dresden.de (S.-C. Li), susanne.passow@psybp.uib.no (S. Passow).

${ }^{1}$ These authors contributed equally to the paper.
}

modulation of working memory maintenance have focused on processes related to prefrontal D1 and D2 receptors (Durstewitz, Seamans, \& Sejnowski, 2000; Phillips, Ahn, \& Floresco, 2004; Williams \& Goldman-Rakic, 1998; Vijyayraghavan et al., 2007). Given that multiple circuits connect striatal regions with regions in the frontal cortex (Alexander, DeLong, \& Strick, 1986; Pennartz et al., 2009), recent human research has begun to investigate the role of striatal dopamine in working memory and attention (e.g., Cools, Clark, \& Robbins, 2004; Frank, Loughry, \& O'Reilly, 2001; Landau, Lal, O'Neil, Baker, \& Jagust, 2005; Lewis, Dove, Robbins, Barker, \& Owen, 2003; McNab \& Klingberg, 2008).

\subsection{Dopamine and attention: evidence from animal and human studies}

Lesion studies in rats have shown that unilateral striatal dopamine depletion increases reaction times of responses contralateral to the lesion side in tasks that require visual attentional orienting (Brown \& Robbins, 1989; Carli, Evenden, \& Robbins, 1985; 
Ward \& Brown, 1996). Deficits in selective attention processes (i.e., the inability to ignore irrelevant stimuli in blocking paradigms) have also been observed in rats with pharmacologically induced hyperdopaminergic activity (Crider, Blockel, \& Solomon, 1986). A more recent study by Brown et al. (2010) investigating neurofibromatosis1 mutant mice with reduced striatal dopamine function found impairments in non-selective and selective attention mechanisms as assessed by a variety of locomotor activities. Moreover, the mutants' attention dysfunctions could be reversed by treatment with methylphenidate, a dopamine agonist commonly used for treating attentional-deficit hyperactivity disorder (ADHD). Of particularly interest for the present study, Bao, Chan, and Merzenich (2001) found that pairing a tone with a transient dopamine signal through stimulation of the ventral tegmental area (VTA) increases the corresponding representation area in the auditory cortex, the selectivity of neural responses, and firing synchrony in response to the specific tone.

In human research, a recent receptor imaging studies used 6$\left[{ }^{18} \mathrm{~F}\right]$ fluoro-L-DOPA (FDOPA) as a radioligand for assessing dopamine synthesis in the striatum. Vernaleken et al. (2007) found that changes in prefrontal blood-oxygen-level-dependent (BOLD) signal during attentional control were positively correlated with dopamine synthesis capacity in the ventral and dorsal striatum. Similarly, it has been observed that changes in BOLD signal in the anterior cingulate cortex and the dorsal lateral prefrontal cortex while processing affective stimuli correlate positively with striatal dopamine synthesis in the caudate and putamen, which indicates that striatal dopamine contributes to attentional processing of affective stimuli (Siessmeier et al., 2006). Furthermore, striatal dopamine synthesis capacity is also related to working memory performance, with dopamine synthesis capacity being higher in individuals with better working memory performance (Cools, Gibbs, Miyakawa, Jagust, \& D'Esposito, 2008). More specifically, as regarding dopamine's effect on mechanisms of selective attention, an early positron emission tomography (PET) study, which used ${ }^{11} \mathrm{C}$-labeled raclopride as the radioligand, found evidence for transient striatal dopamine release while young adults played a video game that required sustained and selective visual attention (Koepp et al., 1998). Also of relevance to the current study, earlier pharmacological studies that used target detection dichotic listening paradigms found that catecholamine antagonists (e.g., haloperidol or droperidol) attenuated the processing negativity, which reflected selective attention, only in later time windows, i.e. at least $200 \mathrm{~ms}$ after stimulus onset (Kähkönen et al., 2001; Shelley et al., 1997). On the other side of the coin, a recent study showed that dopamine agonist (rotigotine) improved hemispatial neglect of patients' performance in visual search tasks that required selective attention (Gorgoraptis et al., 2012).

\subsection{Dopamine and attention: clinical and molecular genetic evidence}

Evidence from clinical research also converges on the view that dysfunctional dopaminergic signaling in the cortical-striatal-thalamic-cortical pathways is one of the causes underlying symptoms of ADHD, such as impaired attentional regulation and poor impulse control (see Arnsten \& Pilszka, 2011; Swanson et al., 2007 for reviews). Abnormality of dopamine signaling in the prefrontal cortex contributes to hypoactivation of the ventral prefrontal and inferior parietal regions (see Casey \& Durston, 2006). Furthermore, in ADHD patients alterations in striatal dopamine transporter (DAT) density (see Fusar-Poli, Rubia, Rossi, Sartori, \& Balottin, 2012 for a meta-analysis of nine receptor imaging studies) as well as reduced volumes of striatal regions, such as the caudate nucleus and the globus pallidus that are rich in dopamine, were observed (Castellanos et al., 2002). Depending on the history of psychostimulant exposures, relative to healthy controls drug naïve ADHD patients tend to show lower DAT density in the striatum (e.g., Hesse, Ballaschke, Barthel, \& Sabri, 2009; Volkow et al., 2007), whereas patients with prior medication treatments tend to show higher DAT density (Fusar-Poli et al., 2012). Altered dopamine transporter density in ADHD patients could change mechanisms of recycling dopamine back into the presynaptic terminal, and consequently would result in suboptimal extracellular dopamine levels (Jones et al., 1998; Shumay, Folwer, \& Volkow, 2010).

Recent molecular genetic studies also showed that the dopamine transporter gene (DAT1) 10R/10R genotype, associated with lower levels of striatal synaptic dopamine and smaller caudate volume, is a risk factor for ADHD (Durston et al., 2005). Investigations of the effects of DAT1 gene genotype on spatial attention in healthy children and adolescents showed that DAT 10R homozygotes tend to perform below the levels of DAT 9R carriers (Bellgrove et al., 2007). Relatedly, a recent study of attentional regulation in healthy younger adults reported that DAT 9R carriers showed a larger effect of inhibition of return, likely reflecting greater attentional flexibility (Colzato, Pratt, \& Hommel, 2010). Furthermore, another genotype also relevant for striatal dopamine function (i.e., the D2 receptor gene, DRD2 C957T) has been found to be associated with individual differences in attentional blink, in line with PET imaging studies suggesting a role for striatal dopamine in the regulation of attentional resources (Colzato, Slagter, de Rover, \& Hommel, 2011).

\subsection{DARPP-32 gene, dopamine modulation, and cognition}

Another well-studied molecular candidate for striatal dopamine signaling is the DARPP-32 protein (now also known as PPP1R1B, protein phosphatase 1, regulatory inhibitor subunit $1 \mathrm{~B})$, which is richly expressed in the striatum. The DARPP-32 protein is phosphorylated by dopamine D1 receptor stimulation, and dephosphorylated by D2 receptor stimulation (Nishi, Snyder, \& Greengard, 1997). The protein modulates striatal dopamine cellular excitability and synaptic plasticity related to the dopamine receptors (Calabresi et al., 2000; Fienberg et al., 1998; Gould \& Manji, 2005). It should be noted, however, given that the striatum integrates excitatory glutamatergic inputs, and there are other neuromodulators, such as adenosine and nitric oxide, which also regulate striatal phosphorylation, it is likely that DARPP-32 also interacts with other neurotransmitters besides dopamine (Svenningsson et al., 2004).

Although as reviewed above the effects of a few other dopamine genes (e.g., the DRD2 or the DAT genotypes) on attention or working memory functions have been studied, much less is known about the potential contributions of the DARPP-32 gene on attentional mechanisms. Extant findings, however, suggest that DARPP-32 may also regulate executive control and attention functions in the frontal cortex via the frontal-hippocampal-striatal pathway. For instance, other than expressions in the striatum, the DARPP-32 protein is also expressed in other regions innervated by dopaminergic projections, such as in the anterior cingulate cortex (Narita et al., 2010) and other regions of the prefrontal cortex (Albert et al., 2002; Kunii et al., 2011). Moreover, the DARPP-32 protein has been shown to modulate the functional interaction between the striatum and the prefrontal cortex (MeyerLindenberg et al., 2007; Frank \& Fossella, 2011) that is critically involved in attention-demanding tasks (e.g., Casey, 2005; Cools et al., 2004; Nagano-Saito et al., 2008). There is also evidence indicating that variations in the DARPP-32 gene affect the functional connectivity between the inferior frontal gygus and the parahippocampus during an associative emotional memory task (Curcic-Blake et al., 2012). Thus, individual differences in mRNA 
expression of the DARPP-32 protein may also account for individual differences in attentional control of auditory processing.

Of particular interest in this context is the allelic variation of a SNP (rs907094) in the DARPP-32 (PPP1R1B) gene. While the precise functional genetic changes invoked by this SNP still need to be elucidated, it is noteworthy that it is located near the splice donor site of the intron between exons 5 and 6 ( $+31 \mathrm{bp}$, using transcript ENST00000254079 as a reference). As such it could affect mRNA processing, e.g. splicing and/or expression. There is already some molecular evidence for the latter, in terms of higher mRNA expression and better striatal receptor function (Calabresi et al., 2000; Fienberg et al., 1998, Meyer-Lindenberg et al., 2007). In human, a haplotype of the DARPP-32 gene that includes the A allele of SNP rs907094 was found to be associated with higher mRNA expressions of the DARPP-32 protein isoforms (MeyerLindenberg et al., 2007). Furthermore, variations in this polymorphism have been found to be associated with fMRI BOLD responses or ERPs in frontal brain networks implicating attention. Individuals carrying a haplotype of the DARPP-32 gene including the A allele of the rs907094 SNP showed greater changes in BOLD response in the striatum as well as greater frontal-striatal connectivity during cognitive performance, among others during attention (Meyer-Lindenberg et al., 2007). In an emotional associative memory task that implicates the frontal-hippocampal network, variations in SNPs of the DARPP-32 gene, including rs907094, were also found to be associated with higher functional connectivity between the inferior frontal gyrus and the parahippocampal gyrus (Curcic-Blake et al., 2012). In the context of reinforcement learning, the A homozygotes of the rs907094 SNP showed a greater advantage than $G$ carriers in learning from positive than from negative outcomes (e.g., Doll, Hutchison, \& Frank, 2011; Frank, Doll, Oas-Terpstra, \& Moreno, 2009; for review, see Frank \& Fossella, 2011). Recently, in a larger sample covering a wider age range from childhood to old age, our own results also showed that feedback-related ERPs assessed at frontal electrodes were larger in A homozygotes of this SNP than any G carriers, particularly in children and older adults (Hämmerer et al., 2013).

\subsection{Aim of study and hypotheses}

The goal of this study was to investigate the effects of dopamine signaling on auditory attention in humans by studying the effects of the DARPP-32 gene on attentional control of auditory perception. To this end, we assessed behavioral performance and ERPs in younger adults while performing a specific variant of the dichotic listening task that was particularly amenable for investigating the effects of conflicts between attentional focus and the relative perceptual saliency of competing auditory inputs (cf. Passow et al., 2012, in press; Westerhausen et al., 2010). Early or late auditory evoked potentials have been shown to reflect neural correlates of sensory-driven or conflict-related processes, respectively. We tested whether the two genotype groups differ in attention modulation of sensory processing as reflected in amplitude differences in P1, N1 or P2 component (e.g., Clark \& Hillyard, 1996; Hillyard, Hink, Schwent, \& Picton, 1973; Lange, Rösler, \& Röder, 2003; Sanders \& Astheimer, 2008). As for conflict-related processing, we focused on a late negativity occurring approximately in the time window of $450-550 \mathrm{~ms}$ after stimulus onset. This late negativity has been shown in previous studies to be sensitive to sensory conflicts between auditory inputs during dichotic listening in younger adults (e.g., Bayazit, Öniz, Hahn, Güntürkün, \& Özgören, 2009). Furthermore, in other cognitive paradigms (e.g., the Stroop interference task) a modulation effect of the ERP in a similar time window was previously shown to reflect the demands of attentional control in conflict processing (e.g., Frühholz, Fehr, \& Herrmann, 2009; Larson, Kaufman, \&
Perlstein, 2009; Liotti, Woldorff, Perez, \& Mayberg, 2000; West \& Alain, 1999) as well as attention orienting (Kanske, Plitschka, \& Kotz, 2011).

Given their higher dopamine function, we expected that A homozygotes of the DARPP-32 gene would show more flexible attentional control of auditory perception than any $G$ carriers, especially under conditions in which attentional focus conflicts with the perceptual saliency of sensory inputs. Accordingly, we also expected that the amplitude of the late negativity (hereafter referred as the N450) would be more strongly modulated by the extent of attentional-perceptual conflict in A homozygotes than in any $G$ carriers.

\section{Materials and methods}

\subsection{Participants}

Twenty-six right-handed younger adults participated in two testing sessions. Handedness was assessed with the Edinburgh Handedness Inventory (Oldfield, 1971). After artifact rejection, one younger participant had to be excluded due to a large number of trials ( $>30 \%$ of total trials) that had to be rejected due to movement artifacts. Genotyping for one additional participant failed, thus the effective sample consisted of 24 younger adults aged 23-35 years (mean age $25.9 \pm 2.7$ years; 11 women). Mean educational level was $13.2( \pm 2.3)$ years. All participants were native speakers of German, gave informed consent, and were paid for participation. The Ethics Committee of the Max Planck Institute for Human Development, Berlin, Germany, approved the study.

\subsection{Genotyping}

DNA was extracted from saliva samples collected using the Orangene ${ }^{\mathrm{TM}}$ DNA self-collection kit following standard user's instructions (DNA Genotek, Inc., 2006). The genotyping was performed at the Max Planck Institute for Molecular Genetics. The DARPP-32 (also known as PPP1R1B) gene is located on human chromosome 17. We genotyped variations in an intronic SNP (rs907094) of the DARPP-32, which involved the Adenine (A) and Guanine (G) exchange (equivalent to a $T$ to $C$ exchange in the complementary strand reported in some of the earlier studies (e.g., Frank et al., 2009). Functional associations of this SNP to various cognitive functions have been reported in previous studies (see details reviewed in Section 1.3. above).

Genotyping was done using a commercially allelic discrimination assay (Assay ID C_ 7452370_1 TaqMan SNP genotyping assay; Applied Biosystems, Forster City, CA, USA). Genotyping was performed in a 384-well format using TaqMan chemistry (using VIC sequence: [5'-TGAGGGGCCTGTGACATGTGGATTA-3' and FAM sequence: 5'-CTGTGGGTCCTCCTTGAGTATACGA-3'] labeled oligonucleotide probes adjacent to the variant basepair) according to manufacturer's genotyping instruction (Applied Biosystems). Genotypes were called after visualization and clustering using Applied Biosystems Autocaller software v1.1. All automatically called genotype clusters were inspected independently and blind to phenotypic status by two lab members and manually recalled where necessary. The genotype distribution in our sample was 12:10:2 (AA:AG:GG), and did not deviate significantly from the Hardy-Weinberg equilibrium $\left(\chi^{2}<1, p>0.05\right)$. Given the low number of $G$ homozygotes, we compared A homozygotes $(n=12)$ with any G carriers $(n=12)$.

Importantly, the two genotype groups were comparable with respect to (i) various relevant demographic covariate measures (e.g., age, sex, and educational level) as well as (ii) other cognitive (e.g., measures of perceptual speed) and sensory (i.e., hearing sensitivity) covariates. Furthermore, the two genotype groups also did not differ with respect to the genotype distributions of other genes relevant to dopamine (DRD2, DRD4, COMT) and cholinergic (CHRNA4) neurotransmission (see statistics in Table 1 )

\subsection{Manipulating attentional focus and perceptual saliency during dichotic listening}

To investigate attentional control of auditory perception in conditions involving conflicts between attention and perception, we combined the classical dichotic listening task with manipulations of attentional focus and perceptual saliency of consonant-vowel (CV) syllables presented to both ears. Perceptual saliency was varied by gradually changing the degree of input intensity differences between the ears, either favoring the right or left ear. As in the classical dichotic listening task, attentional focus was varied by instructing the participants to attend to both ears or to focus either on the right or left ear.

The syllables consisted of three voiced $(/ \mathrm{b} /, / \mathrm{d} /, / \mathrm{g} /)$ and three unvoiced $(/ \mathrm{p} /, / \mathrm{t} /$, $/ \mathrm{k} /$ ) consonants that were combined with the vowel /a/. Only syllables with the same voicing were combined, resulting in 12 different dichotic syllable pairs. The mean stimulus duration was $400 \mathrm{~ms}$ and the two syllables were temporally 
Table 1

Comparability of the two DARPP-32 genotype groups in demographic characteristics, as well as other relevant sensory, cognitive, and genetic variables.

\begin{tabular}{|c|c|c|c|c|c|c|}
\hline & DARPP-32 genotype & e Mean & \multicolumn{2}{|c|}{ SD } & $t$ & $p$ \\
\hline Age & $\begin{array}{l}\text { AA } \\
\text { Any G }\end{array}$ & $\begin{array}{l}26.33 \\
25.50\end{array}$ & 2. & & 0.76 & 0.45 \\
\hline Years of & $\begin{array}{l}\text { Aucation } \\
\text { Any G }\end{array}$ & $\begin{array}{l}12.83 \\
13.50\end{array}$ & 1. & & -0.70 & 0.49 \\
\hline Hearing & $\begin{array}{l}\text { AA } \\
\text { Any G }\end{array}$ & $\begin{array}{r}4.83 \\
6.00\end{array}$ & $\begin{array}{l}4 . \\
3 .\end{array}$ & & -0.75 & 0.46 \\
\hline Digit sym & Any G & $\begin{array}{l}70.00 \\
73.00\end{array}$ & \multicolumn{2}{|c|}{13.54} & -0.51 & 0.62 \\
\hline Identical & $\begin{array}{l}\text { icture (RT) } \\
\text { AA } \\
\text { Any G }\end{array}$ & $\begin{array}{l}1864.99 \\
1996.35\end{array}$ & & 239.16 & -0.99 & 0.33 \\
\hline Sex & $\begin{array}{l}\text { AA } \\
\text { Any G }\end{array}$ & $\begin{array}{l}\text { Males } \\
6 \\
7\end{array}$ & $\mathrm{Fe}$ & ales & $\begin{array}{l}\chi^{2} \\
0.17\end{array}$ & $\begin{array}{l}P \\
0.68\end{array}$ \\
\hline CHRNA4 & $\begin{array}{l}\text { AA } \\
\text { Any } G\end{array}$ & $\begin{array}{l}\text { AA } \\
3 \\
5\end{array}$ & 9 & & 0.75 & 0.39 \\
\hline DRD2 & $\begin{array}{l}\text { AA } \\
\text { Any G }\end{array}$ & $\begin{array}{l}\text { AA } \\
8 \\
9\end{array}$ & $\begin{array}{l}4 \\
3\end{array}$ & & 0.20 & 0.65 \\
\hline DRD4 & $\begin{array}{l}\text { AA } \\
\text { Any G }\end{array}$ & $\begin{array}{l}\text { AA } \\
8 \\
10\end{array}$ & $\mathrm{Ar}$ & & 0.89 & 0.35 \\
\hline COMT & $\begin{array}{l}\text { AA } \\
\text { Any G }\end{array}$ & $\begin{array}{l}\text { Met/Met } \\
1\end{array}$ & $\begin{array}{l}\text { Val/Met } \\
6 \\
5\end{array}$ & $\begin{array}{l}\text { Val/Val } \\
5 \\
3\end{array}$ & 2.39 & 0.30 \\
\hline
\end{tabular}

synchronized to have the same onset times for the left- and right-ear channels. The discriminability of the syllables was tested prior to the experiment. In the extensive behavioral version of the task, perceptual saliency varied across 9 levels of interaural intensity difference by decreasing the intensity of either the right or left ear in $5 \mathrm{~dB}$ steps until a maximum of $20 \mathrm{~dB}$ difference was reached (comparable to Passow et al., 2012, in press). Thus, altogether there were 4 levels favoring the left ear, $L>R$ ([-20], [-15], [-10], [-5]), 4 levels favoring the right ear, $R>L([20],[15]$, [10], [5]), and one neutral (same input intensity to both ears, $L=R([0])$. The neutral condition served as baseline intensity and was adapted to each participant's individual hearing threshold at $500 \mathrm{~Hz}$ (see Section 2.4). The dense sampling of intensity differences in the behavioral version of the task allowed us to compute an independently assessed measure of attentional flexibility in attending to either ear (cf. Passow et al., in press) for investigations of the gene-brain-behavior relations.

As for the EEG version of the task, the 9 levels of inter-aural intensity differences in the behavioral version were reduced to 3 levels by decreasing the intensity of either the right or left ear by $10 \mathrm{~dB}$ to obtain more trials per condition to enhance the signal-to-noise ratio of EEG assessments. Thus, in the EEG version, there was one condition favoring the left ear, $(L>R([-10])$, one favoring the right ear $(R>L$ ([10]), and one neutral condition with the same input intensity to both ears $(L=R$ ([0]). Each of the 12 dichotic syllable pairs was presented 9 times for each of the 3 perceptual saliency levels, resulting in a total of 324 intensitystimulus pairs for each of the three conditions of attentional focus. These trials were further split into four testing runs of 81 trials each with a short 3-min break in between runs. Altogether, this resulted in a total of 972 trials for the EEG assessment.

Attentional focus was manipulated by three different instructions (cf. Hugdahl \& Andersson, 1986): In the neutral focus (NF) condition, participants were asked to report the syllables they heard most clearly irrespective of ear of input, whereas in the focused attention conditions they were asked to focus either on the right ear (FR) or on the left ear (FL) and report only the syllables presented to the attended ear. The NF condition was always completed first to avoid carry-over effects from the FR or FL conditions (Hiscock \& Stewart, 1984). Afterwards, FR and FL were intermixed and individually counterbalanced. As we simultaneously manipulated attentional focus and perceptual saliency, the degree of attentional-perceptual conflict was systematically varied as well. When perceptual saliency and attentional focus favored the same ear there was no conflict; whereas there was an attentional-perceptual conflict when the attended ear and perceptual saliency favored opposing ears.

\subsection{Procedure}

The data were collected in two separate experimental sessions on two separate days. In the first session, all participants first completed the extensive behavioral version of the task. In a second session, EEG was recorded while the participants conducted a variant of the task with 3 levels of inter-aural intensity difference. All participants were screened for hearing acuity and sensitivity to inter-aural threshold differences for the frequencies 250,500,1000, 2000, and $3000 \mathrm{~Hz}$ by using a pure-tone audiometer (MAICO Diagnostics MA 51, Berlin, Germany).

The stimulus intensity was individually adjusted by adding a constant of $65 \mathrm{~dB}$ to the participant's personal hearing threshold at $500 \mathrm{~Hz}$ (mean of the range from 0 to $1000 \mathrm{~Hz}$ ), as the highest amplitude in all the presented CV syllables was in the frequency range below $1000 \mathrm{~Hz}$. This ensured equal extent of intensity manipulation across individuals. All testing was performed in a sound-attenuated booth. Presentation of the stimuli and response collection were controlled via E-Prime 1.1 software run on a PC. All stimuli were presented using insert earphones (ER 3A Insert Earphone, Etymotic Research, Inc., Elk Grove Village, IL, USA)

\subsection{Electrophysiological data recording}

EEG was recorded continuously (BrainAmp DC amplifiers, Brain Products $\mathrm{GmbH}$, Gilching, Germany) from $64 \mathrm{Ag} / \mathrm{AgCl}$ electrodes placed according to the 10-10 system in an elastic cap (Braincap, BrainVision), using BrainVision Recorder The sampling rate was $1000 \mathrm{~Hz}$ with a bandpass filter applied in the range of 0.01$100 \mathrm{~Hz}$. EEG recordings were referenced online to the right mastoid. The ground was positioned above the forehead. Impedances were kept below $5 \mathrm{k} \Omega$. Vertical and horizontal electro-oculograms were recorded next to each eye and below the left eye. Using BrainVision Analyzer, the recorded data were digitally re-referenced to a linked mastoid reference. EEG recordings were bandpass-filtered $(0.05-25 \mathrm{~Hz})$ and segmented into stimulus-locked time epochs of $100 \mathrm{~ms}$ prestimulus to $800 \mathrm{~ms}$ postonset. Thereafter the epochs were corrected for eye movements using the Gratton and Coles algorithm (Gratton, Coles, \& Donchin, 1983), and further artifacts were rejected based on a maximum admissible voltage step $(50 \mu \mathrm{V})$, and a maximum admissible absolute difference between two values in a segment $(150 \mu \mathrm{V})$. Across all conditions an average of $11 \%$ of the trials were rejected. The number of rejected trials did not significantly differ between conditions (all $p \geq 0.05$ ). Baseline corrections were applied automatically on the epoched data with respect to a $100 \mathrm{~ms}$ prestimulus baseline. ERPs were then obtained by separately averaging across trials for each electrode and condition for each subject first, and then across subjects.

\section{Data analysis}

The behavioral and ERP data were analyzed to examine DARPP32 genotype effects in three main aspects: (a) the interactions between attentional focus and perceptual saliency; (b) an index of attentional flexibility; and (c) early sensory selection and later conflict-related processing that are reflected in the ERPs. Furthermore, the genotype effects on ERP components reflecting early auditory processing were also analyzed. 


\subsection{Analysis of behavioral data}

Genotype effects on the interaction between attentional focus and perceptual saliency in the behavioral as well as in the EEG session were analyzed with respect to the auditory laterality index (LI). The LI represents the extent of correct right-ear (RE) reports in relation to correct left-ear $(\mathrm{LE})$ reports (i.e., $((\mathrm{RE}-\mathrm{LE}) /(\mathrm{RE}+\mathrm{LE}) \times 100)$. It is used as an index of hemispheric lateralization in verbal processing and ranges from $-100 \%$ to $100 \%$ (Marshall, Caplan, \& Holmes, 1975). Positive LIs indicate a right-ear advantage (REA, more reports from the right ear), whereas negative LIs indicate a left-ear advantage (LEA, more reports from the left ear). The LIs for DARPP-32A homozygotes and any $G$ carriers were entered in repeated-measures ANOVA with attentional focus (NF, FR, FL) and the perceptual saliency conditions ( 9 conditions in the behavioral and 3 conditions in the EEG session) as withinsubject factors and DARPP-32 genotype and sex as between-subject factors. Including sex as a between-subject factor did not reveal significant main or interaction effects (all $p>0.05$ ) in any of the ANOVAs; thus, all subsequent analyses were performed by collapsing across males and females. In addition, we computed a behavioral measure to investigate the gene-brain-behavioral relations that was termed Selective Attention Index (ATTIndex). This measure of attentional flexibility was computed for the extended behavioral and EEG versions of the task. Depending on versions of the task, the ATTIndex was computed by calculating the differences between (a) the laterality indices in FR and NF conditions ( $\mathrm{LI}_{\mathrm{FR}}-\mathrm{LI}_{\mathrm{NF}}$ ) and (b) the laterality indices in $\mathrm{NF}$ and $\mathrm{FL}$ conditions $\left(\mathrm{LI}_{\mathrm{NF}}-\mathrm{LI}_{\mathrm{FL}}\right.$ ) for each of the 9 (or 3) levels of perceptual saliency. Afterwards, the differences were then summed and the mean of the summed differences was taken as an index of the extent to which the participant could selectively attend either to inputs from the right- or left-ear (cf. Passow et al., in press). Independent $t$-tests were used to test whether ATTIndices derived from the behavioral or the EEG session differed significantly between the two genotype groups.

\subsection{Analyses of EEG data}

For analyses of DARPP-32 genotype effects on cortical evoked potentials, mean latencies and mean amplitudes of relevant ERP components were entered into repeated-measure ANOVAs with conflict (conflict vs. no conflict) and attended ear (FR, FL) as withinsubject factors and DARPP-32 genotype and sex as between subject factors. We tested for genotype effects in attention regulation of early auditory processing, as reflected by differences in the amplitude of the P1, N1 and P2 components (e.g., Clark \& Hillyard, 1996; Hillyard et al., 1973; Lange et al., 2003; Sanders \& Astheimer, 2008). Informed by previous findings (Ceponiene, Westerfield, Torki, \& Townsend, 2008) and in line with the scalp topography of the present data (see Fig. 3), these analyses focused on fronto-central sites (FCz, C1, C2). After visual inspection of the grand average ERP data, peak amplitude of the P1, N1, and P2 were defined as the most positive (P1 and P2) or negative peak (N1) in the individual averages in the following time windows: P1: 80-120 ms, N1: 120$200 \mathrm{~ms}$ and P2: 200-300 ms after stimulus onset. Peak latency of all components in each of the conditions was indexed as the averaged time of the individual ERP peak amplitude across trials.

Furthermore, we were interested in analyzing DARPP-32 genotype effects on the late N450 modulation effect, which has been previously shown to reflect the deployment of attentional resources when cognitive conflict (e.g., Larson et al., 2009; West \& Alain, 1999), error monitoring (Niedeggen \& Rösler, 1999) or attention orienting (Kanske et al., 2011) was involved. Previous studies showed a more posterior distribution of the N450 component when not using the classical Stroop but other conflict paradigms (e.g., Frühholz et al., 2009; Schirmer \& Kotz, 2003). Guided by these earlier findings and the scalp topography of the
N450 modulation effect obtained in the present study (see Fig. 4), the analyses of electrophysiological data were focused on the parietal (i.e., the Pz, P3, and P4 electrodes) region of interests (ROI). Based on earlier results (Bayazit et al., 2009) and visual inspections of the grand average ERP waveform of the present data, ERP peak amplitudes for analyzing the N450 modulation effect were defined as the most negative peak in the individual averages between 450 and $550 \mathrm{~ms}$ after stimulus onset. Mean peak ERP amplitudes in each of the conditions (i.e., conflict vs. no conflict) were parameterized as the mean voltage in a range of $25 \mathrm{~ms}$ before and $25 \mathrm{~ms}$ after each individual peak across trials. The N450 modulation effect was defined as the difference between the mean N450 amplitudes in conditions with attentional-perceptual conflict and no conflict (i.e., $\mathrm{N} 450_{\text {high }}$ conflict $-\mathrm{N} 450_{\text {no conflict }}$ ) in the time window of $450-550 \mathrm{~ms}$ after stimulus onset. Mean N450 latency in each of the conditions was indexed as the averaged time of the individual ERP peak amplitude across trials.

Including sex as a between-subject factor in the repeatedmeasures ANOVAs did not reveal any main or interaction effects (all $p>0.05$ ). Therefore, sex was dropped as a factor in all analyses reported below. Mean latencies of the ERP components of interest did not vary reliably as a function of attentional focus, perceptual saliency, or genotype (all $p>0.05$ ), and thus will not be reported in detail. Whenever sphericity assumptions were violated $(p<0.05$, Mauchly's test) the Greenhouse-Geisser correction was applied, and adjusted degrees of freedom and $p$ values of the analyses are reported. Effect sizes of main or interaction effects are given as $\eta^{2}$, representing the proportion of variance of the dependent factor explained by the independent variable. Effect sizes of follow-up t-tests were given as Cohen's $d$. For all the analyses the alpha level was set $p=0.05$.

\section{Results}

\subsection{Behavioral performance}

A three-way repeated-measures ANOVA with the LIs derived from the behavioral session as dependent variable revealed significant main effects of attentional focus, $F(1.19,26.12)=40.84, p<0.05, \eta^{2}=.25$, and perceptual saliency, $F(2.15,47.26)=120.36, p<0.05, \eta^{2}=0.54$. The two-way attentional focus $\times$ perceptual saliency interaction, $F$ $(5.08,111.82)=3.62, p<0.05, \eta^{2}=0.01$, was also significant. Of particular interest are the interactions involving DARPP-32 genotype. Both the two-way attentional focus $\times$ DARPP-32 genotype interaction, $F$ $(1.19,26.12)=12.16, \quad p<0.05, \eta^{2}=0.07$, and the three-way attentional focus $\times$ perceptual saliency $\times$ DARPP-32 genotype interaction, $F$ $(5.08,111.82)=2.93, p<0.05, \eta^{2}=0.01$, were significant. The two-way perceptual saliency $\times$ DARPP-32 genotype interaction was not significant $(p>0.05)$. To follow up the significant three-way interaction, separate analyses for each genotype group showed a larger effect of attentional focus in DARPP-32 A homozygotes, $F(1.05,11.60)=32.33$, $p<0.05, \eta^{2}=0.55$, and a much weaker effect in any $G$ carriers, $F$ $(1.43,15.75)=9.38, p<0.05, \eta^{2}=0.06$. The main effect of perceptual saliency was also significant in both groups; however, in contrast to the effect of attentional focus, the effect was weaker in DARPP-32 A homozygotes, $F(1.70,18.67)=40.71, p<0.05, \eta^{2}=0.37$, than in any $G$ carriers, $F(2.68,29.45)=85.61, p<0.05, \eta^{2}=0.76$. Together these patterns of results indicate that DARPP-32 genotype affects interactions between attentional focus and perceptual saliency. In A homozygotes, the LIs clearly varied as a function of instructed task goals (i.e., attending to the right or left ear, or attending to both), whereas in any $\mathrm{G}$ carriers, auditory perception was mainly driven by the perceptual saliency of the stimulus inputs, regardless of attentional focus (see Fig. 1A). 
A
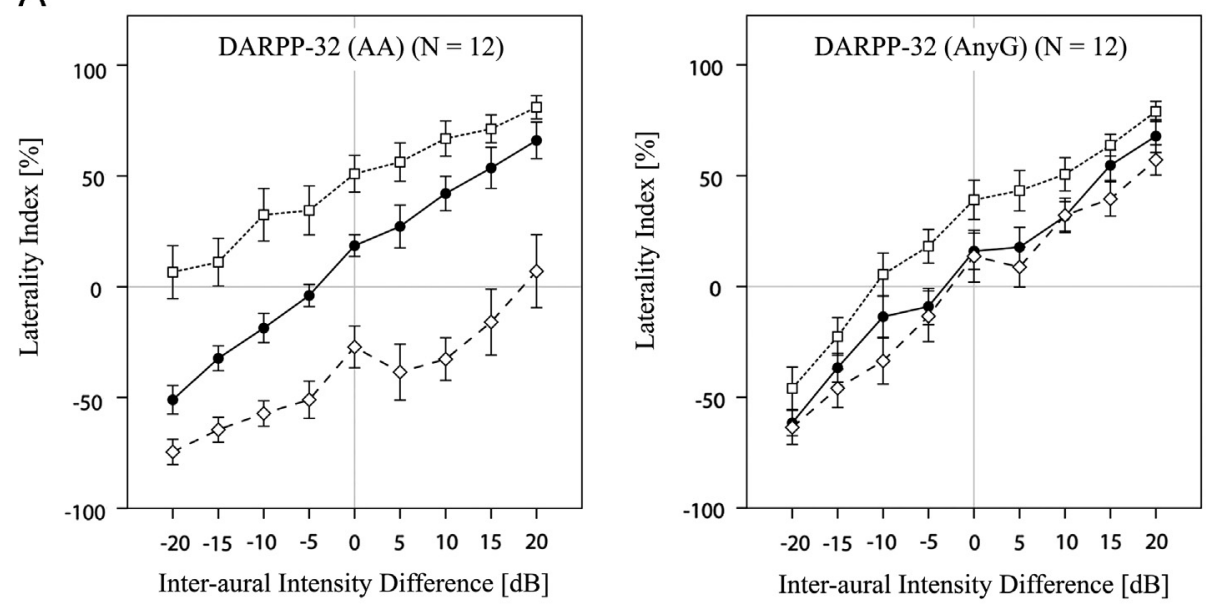

B
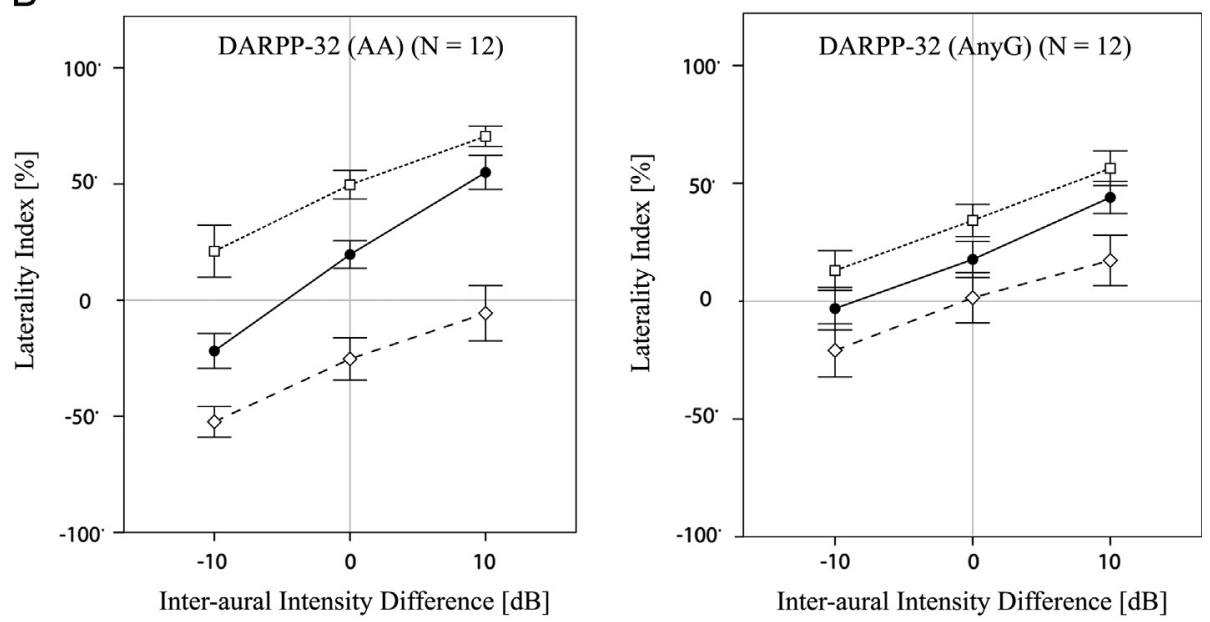

- Neutral-Focus
$\prec-$ Focused-Right
Focused-Left

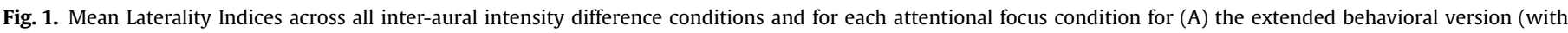

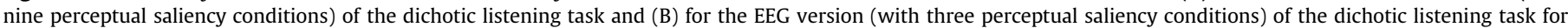
DARPP-32 A homozygotes (left panels) and DARPP-32 any G carriers (right panels). Error bars indicate 1 SE of the mean.

The three-way repeated-measures ANOVA analyzing the LIs assessed in the EEG version of the task with three levels of perceptual saliency also revealed a similar pattern of results (compare Fig. 1B with 1A). The analyses revealed significant main effects of attentional focus, $F(1.23,27.09)=30.99, p<0.05, \eta^{2}=0.39$, and perceptual saliency, $F$ $(1.32,29.03)=120.36, p<0.05, \eta^{2}=0.32$. The two-way attentional focus $\times$ perceptual saliency interaction, $F(1.73,30.05)=4.79, p<0.05$, $\eta^{2}=0.01$, and of particular interest, the two-way attentional focus $\times$ DARPP-32 genotype interaction, $F(1.23,27.09)=4.05, p<0.05$, $\eta^{2}=0.05$, were also significant. The three-way attentional focus $\times$ perceptual saliency $\times$ genotype interaction was only marginal in this case $(p=0.16)$, presumably reflecting the more restricted range of perceptual saliency in the EEG version of the task. Follow-up analyses of the significant attentional focus $\times$ DARPP-32 genotype interaction for each genotype group separately revealed a larger effect of attentional focus in DARPP-32 A homozygotes, $F(1.14,12.51)=28.45$, $p<0.05, \eta^{2}=0.55$, and a weaker effect in any $G$ carriers, $F$ $(1.24,13.62)=6.38, p<0.05, \eta^{2}=0.23$. The main effect of perceptual saliency was significant in DARPP-32 A homozygotes, $F(1.26,13.80)=$ 65.22, $p<0.05, \eta^{2}=0.32$ as well as in any $G$ carriers, $F(1.30,14.28)=$ 39.96, $p<0.05, \eta^{2}=0.34$.

In line with the results reported above, independent $t$-tests also revealed significantly higher mean ATTIndices in DARPP-32 A homozygotes compared to any $\mathrm{G}$ carriers in the behavioral session, $t(16.76)=3.55, p<0.05, d=1.45$, and in the EEG session, $t(22)=$ 2.11, $p<0.05, d=0.89$ (see Fig. 2A).

Other than the above findings specific to the aims of our study, we also found the commonly observed right-ear advantage (REA) effect of auditory verbal processing (i.e., more report of verbal stimuli presented to the right relative to the left ear; see Hugdahl et al., 2003 for reviews) in the neutral focus condition of our experiment when both ears were presented with the same input intensity. Specifically, we observed an effect of REA as reflected in the main effect of ear in the behavioral session, $F(1,22)=12.90$, $p \leq 0.05$, as well as in the EEG session, $\mathrm{F}(1,22)=15.12, p \leq 0.05)$. The REA effect, however, was not related to attentional flexibility as reflected in the selective attention indices $(p s>0.05)$ nor to genotype ( $p s>0.05$ for ear $\times$ genotype interaction).

\subsection{Relations between cortical evoked potentials and task performance}

At the sample level without subdividing the two genotype groups, the mean averaged amplitude of the N1 component across all conditions correlated positively with the ATTIndex of the behavioral, $r=0.49, p<0.05$, and EEG session, $r=0.48, p<.05$ 
A

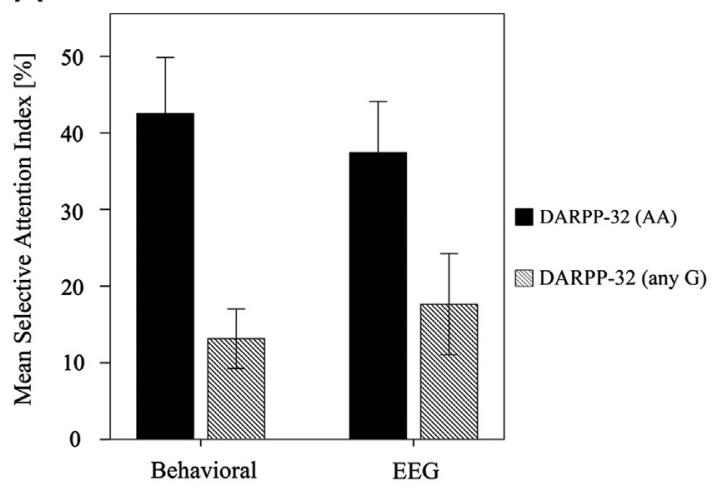

B

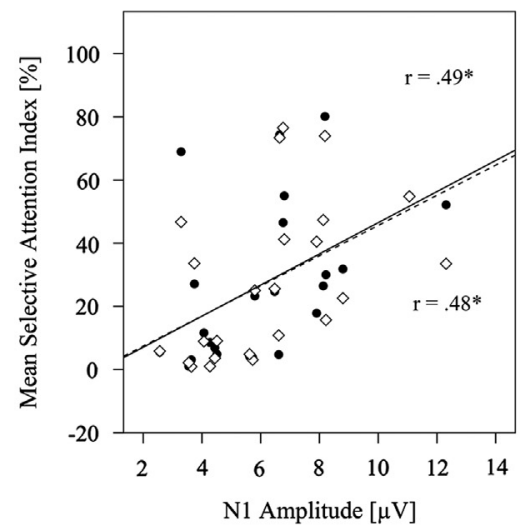

C

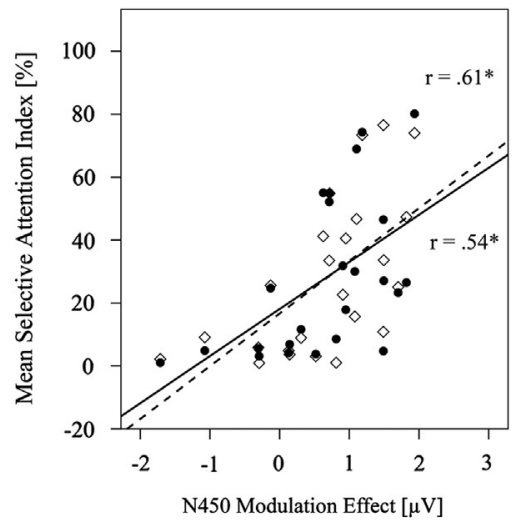

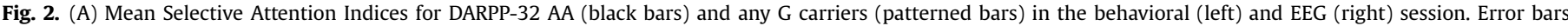

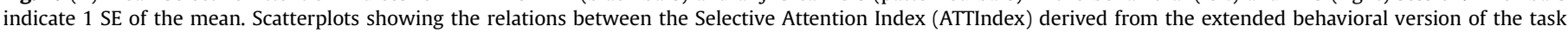
(black circles, solid line) as well as the EEG version of the task (open rhombs, dashed line) and the N1 amplitude (B) and the N450 modulation effect (C) $\left({ }^{*} p<0.05\right)$.

(see Fig. 2B). Furthermore, we were interested in the late evoked potential (N450), which reflects attentional regulation of conflict resolution when attentional focus conflicts with perceptual saliency (cf. Passow et al., in press). At the sample level, the magnitude of N450 modulation effect (i.e., the enhancement of N450 magnitude in the conflict relative to the no-conflict condition) correlated positively with the ATTIndex derived from the behavioral session, $r=0.54, p<0.05$, and the EEG session, $r=0.61$, $p<0.05$ (see Fig. 2C). Individuals who showed a stronger N450 modulation in response to conflicts between attentional focus and perceptual saliency also yielded higher ATTIndices. Thus, N450 modulation reflected individual differences in the flexible allocation of attentional control.

\subsection{Genotype Effect on N1 at frontal-central electrodes}

In light of results from earlier studies (Ceponiene et al., 2008) and the scalp topography of our data (see Fig. 3B), we focused on N1 component derived from the frontal-central electrodes. The repeated-measure ANOVA for the entire sample revealed a significant DARPP-32 genotype effect on the $\mathrm{N} 1$ component, $F(1,22)=$ $10.41, p<0.05, \eta^{2}=0.32$. This effect, however, did not interact with conflict $(p>0.05)$, reflecting that the $\mathrm{N} 1$ amplitude was larger in DARPP-32 A homozygotes than in any $G$ carriers in all conditions independent of whether attentional-perceptual conflict was involved (see Fig. 5). As comparisons, we also analyzed two other early auditory evoked potentials: In contrast to N1, no genotype effects were found for the P1 and P2 components, $p s>0.05$ (see Fig. 3A and C).

\subsection{Genotype Effect on N450 at parietal electrodes}

Guided by previous studies showing a more posterior distribution of the N450 when not using the classical Stroop but other conflict paradigms (e.g., Frühholz et al., 2009; Schirmer \& Kotz, 2003) and the scalp topography from our data (see Fig. 4), we focused on N450 component derived from parietal electrodes. Results of the repeated measures ANOVA revealed a main effect of conflict, $F(1,22)=13.66, p<0.05, \eta^{2}=0.03$, and a trend for a conflict $\times$ DARPP-32 genotype interaction, $F(1,22)=2.39, p=0.09$, $\eta^{2}=0.01$. As most methods of multiple comparisons, including Tukey's test, can be applied regardless of whether the $F$ test is significant (Ryan, 1959a, 1959b; Wilcox, 1987), we followed up the marginally significant interaction separately for the two genotype groups. The results indicated a main effect of conflict in DARPP-32
A homozygotes, $F(1,11)=29.71, p<0.05, \eta^{2}=0.11$, but not in any $\mathrm{G}$ carriers, $p>0.05$. Follow-up $t$-test in A homozygotes revealed a significantly larger N450 in conditions involving conflict between attentional focus and perceptual saliency than in conditions without such conflicts, $t(11)=-2.37, p<0.05, d_{z}=0.68$ for the attending right condition and $t(11)=-3.36, p<0.05, d_{z}=0.97$ for the attending left condition (see Fig. 6).

\section{Discussion}

The present study provides novel evidence for an association between the DARPP-32 gene (SNP rs907094) and attentional control of auditory perception. Effects of the DARPP-32 genotype were observed in behavioral measures reflecting the flexibility of attentional control and cortical evoked potentials associated with attention for early sensory selection (N1 amplitude) and upregulation of cortical activity for conflict resolution (N450 amplitude). At the behavioral level, the A homozygotes of this gene, who based on past evidence are characterized by higher mRNA expression and better striatal D1 receptor function (Calabresi et al., 2000; Fienberg et al., 1998; Meyer-Lindenberg et al., 2007), were more flexible in selectively attending to either ear dependent on task requirements. In contrast, any $\mathrm{G}$ carriers were less able to regulate their attention according to task demands. As a result, their performance was primarily driven by the perceptual saliency regardless whether saliency was in conflict with the current task goal.

At the brain level, DARPP-32 (SNP rs907094) genotype also influenced the amplitude difference between the conflict and no conflict condition of the N450, a late negativity peaking around $450 \mathrm{~ms}$ after stimulus onset. Of particular interest, the A homozygotes who showed more flexible attentional control also showed an attention-related modulation of the N450, whereas the any G carriers did not. In addition, A homozygotes also showed larger N1 amplitudes than any $\mathrm{G}$ carriers, independent of attentional-perceptual conflict. Both the N450 and the N1 amplitudes correlated with behavioral measures of attentional control, confirming the internal validity of the observed ERP genotype differences. As it is the case for candidate gene association studies, given the small size of our sample, the associations among the DARPP32 gene, behavior, and ERP components found in this study need to be replicated with independent samples before drawing firm conclusions. With this caveat in mind, we discuss some potential implications of the present results. 
A

DARPP-32 (AA)

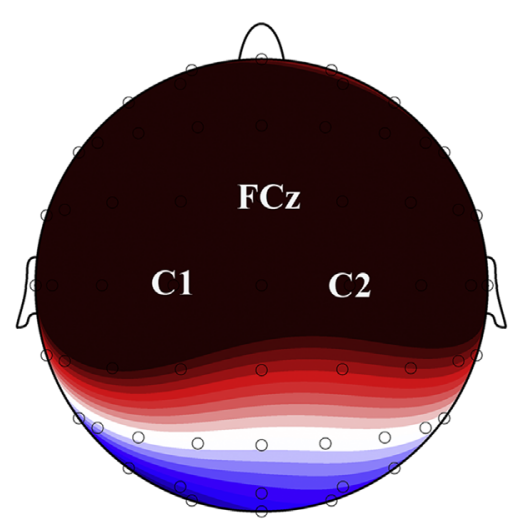

P1

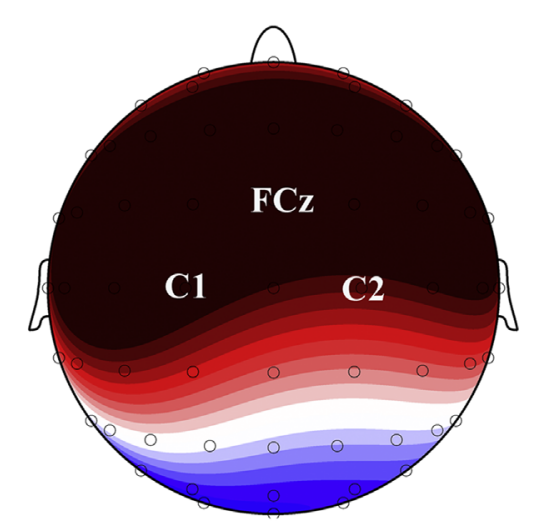

$80-120 \mathrm{~ms}$

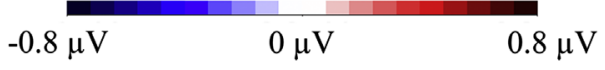

B

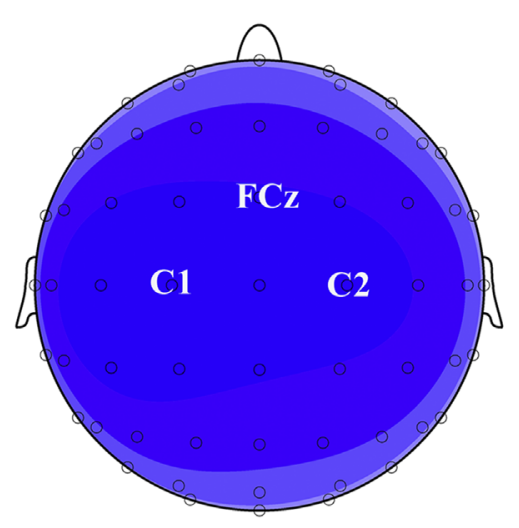

N1

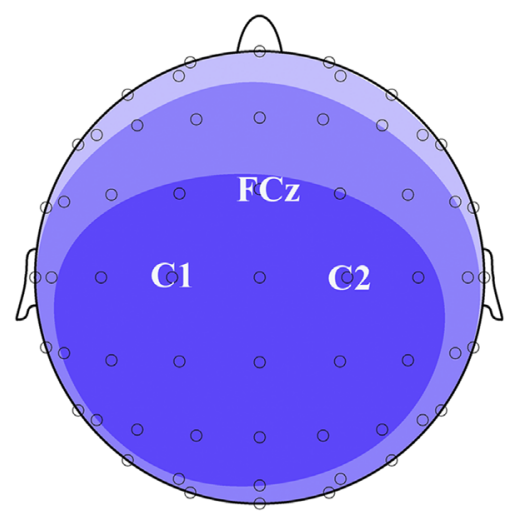

$120-200 \mathrm{~ms}$
DARPP-32 (any G)
C

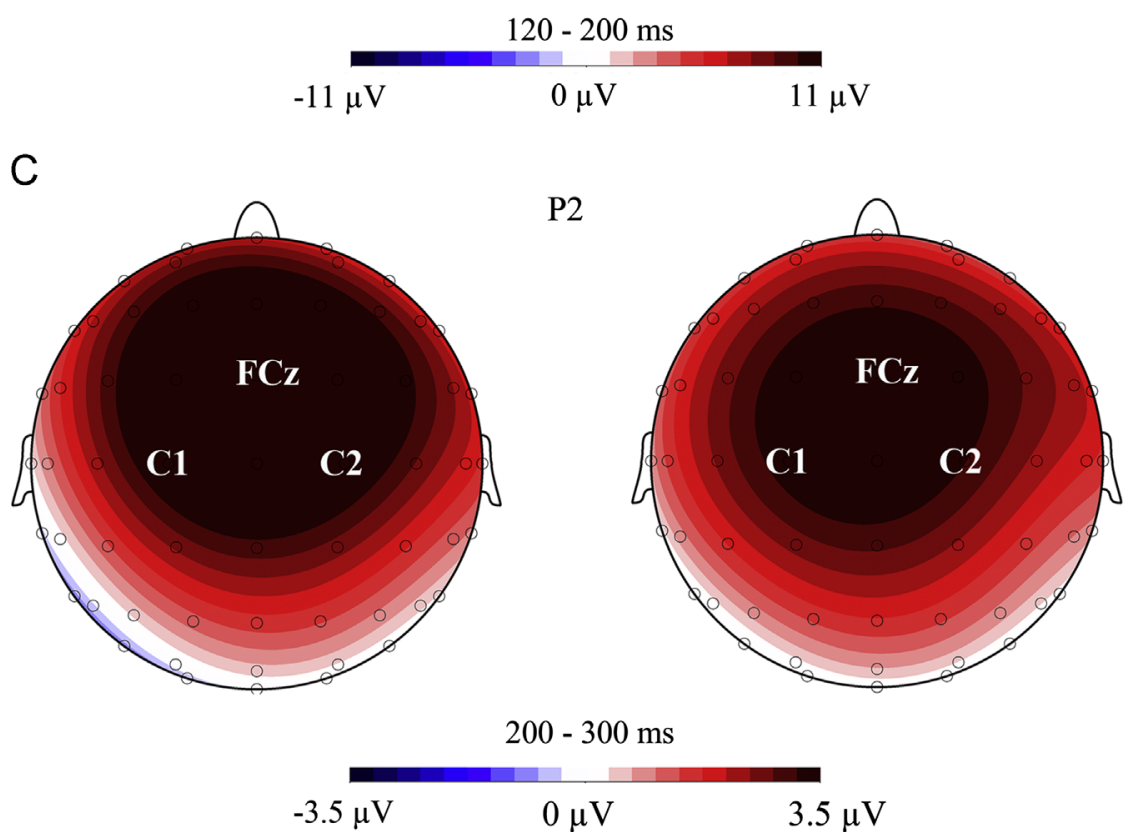

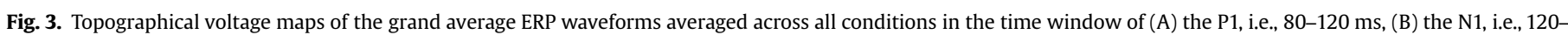

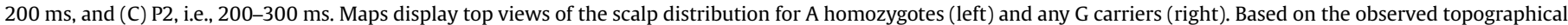
map, the fronto-central ( $\mathrm{FC}, \mathrm{C} 1, \mathrm{C} 2)$ region of interest was used to define the three early EPR components (see main text for details). 


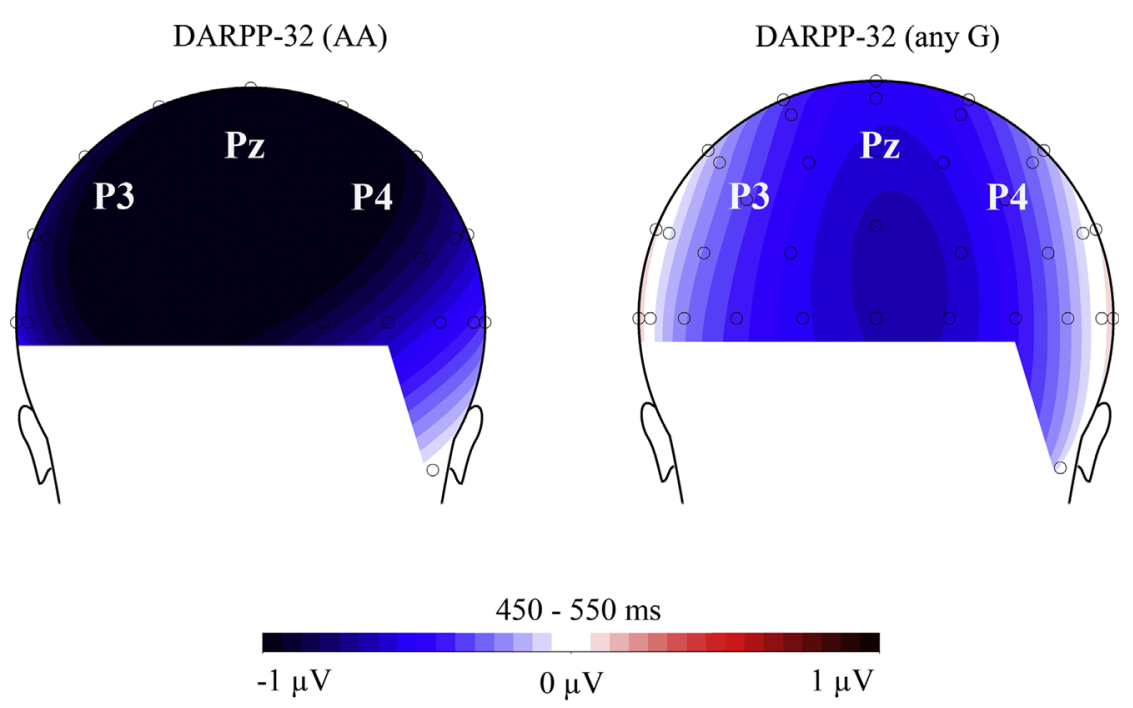

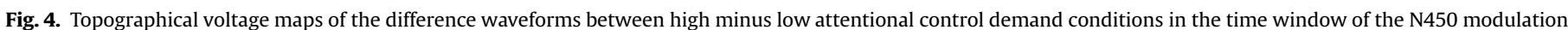

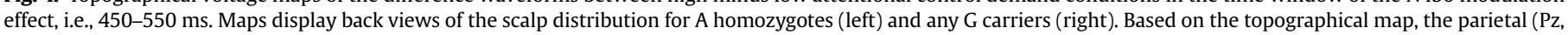
$\mathrm{P} 3, \mathrm{P} 4)$ region of interest was used to derive the N450 component (see main text for details).

\section{DARPP-32 (AA)}
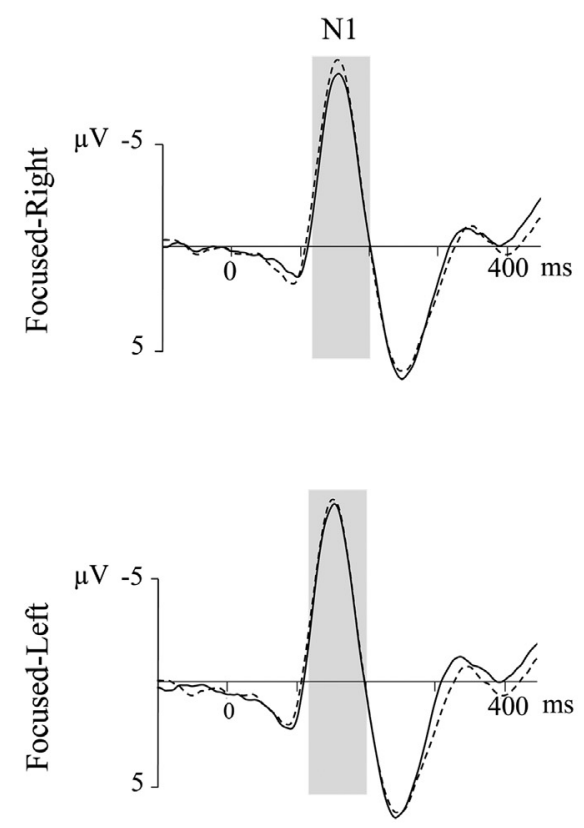

Right ear louder than left ear
DARPP-32 (any G)
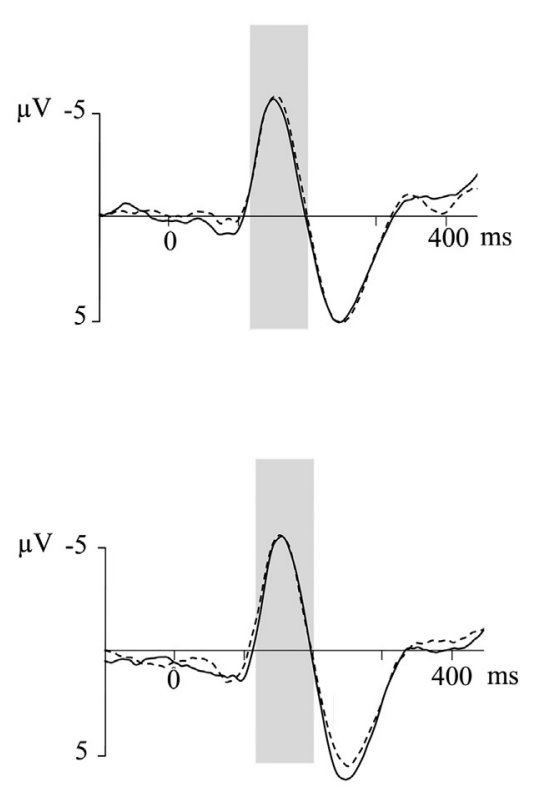

Left ear louder than right ear

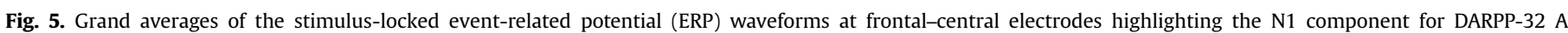

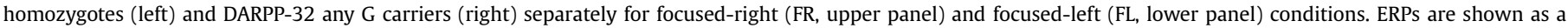
function of inter-aural intensity difference: right ear $>$ left ear and left ear $>$ right ear.

\subsection{DARPP-32 genotype effect and dopamine's role in attentional control of auditory perception}

The present findings complement the results of other studies indicating that variations in dopamine functioning influence working memory (e.g., Cools et al., 2004; Frank et al., 2001; Landau et al., 2005; Lewis et al., 2003; McNab \& Klingberg, 2008), executive control (e.g., Hesse et al., 2009; Siessmeier et al., 2006; Vernaleken et al., 2007; Volkow et al., 2007), and selective attention (e.g., Gorgoraptis et al., 2012; Kähkönen et al., 2001; Shelley et al., 1997). Human studies of striatal dopaminergic modulation of attention primarily investigated attentional control in the context of complex visual perception, such as video games (Koepp et al., 1998) and affective scenes (Siessmeier et al., 2006), or in the context of other cognitive processes such as Stroop interference (Vernaleken et al., 2007), visual attention as assessed by the Trail-Making test (Meyer-Lindenberg et al., 2007) and the attentional blink effect (Colzato et al., 2011). Our findings of DARPP32 genotype effects on the behavioral performance and cortical evoked potentials that reflect attentional control of auditory perception when processing competing sensory information extend these previous findings. Specifically, our finding of A homozygotes performed better and showed a larger amplitude of the late N450 component in conditions that demanded more 
DARPP-32 (AA)
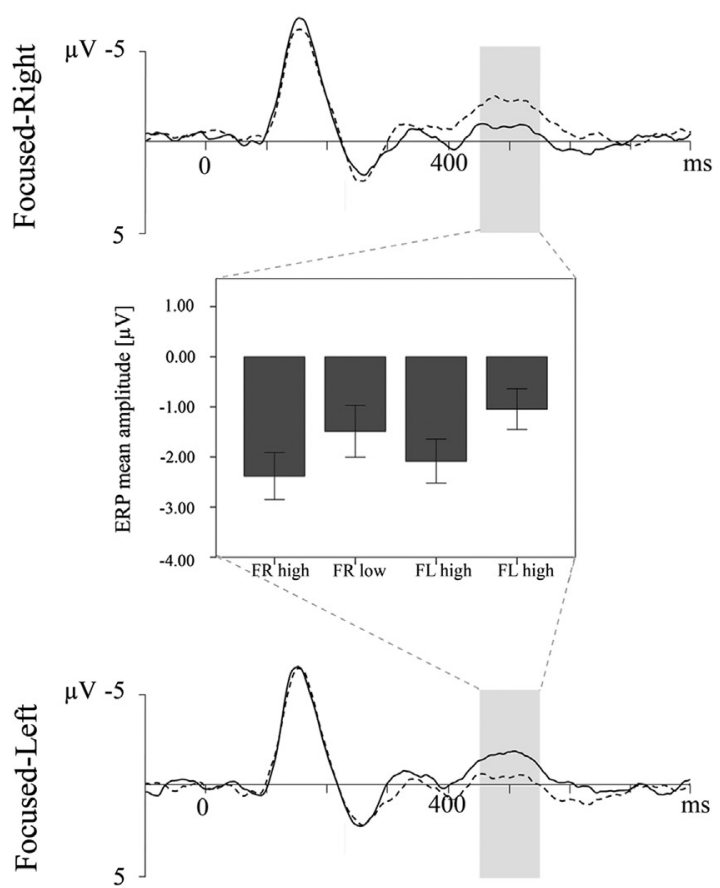

Right ear louder than left ear
DARPP-32 (any G)

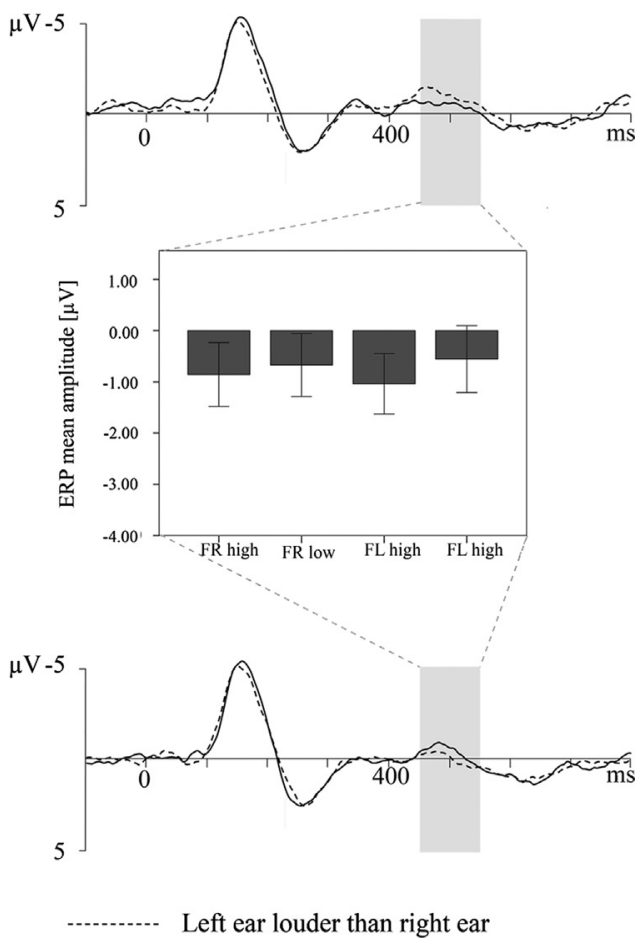

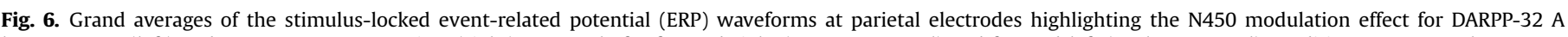

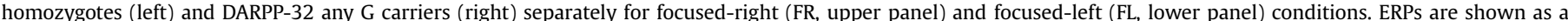

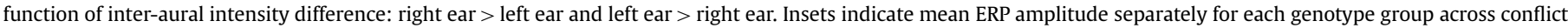
and no conflict conditions in FR and FL conditions. Error bars indicate 1 SE of the mean.

selective attention lend further support to earlier results showing pharmacological effects of dopamine antagonist (Kähkönen et al., 2001; Shelley et al., 1997) and agonist (Gorgoraptis et al., 2012) in modulating selective auditory and visual attention. The late N450 amplitude modulation effect found in the current study parallels effects of dopamine antagonists on later processing negativity (i.e., at least $200 \mathrm{~ms}$ after stimulus onset) that was associated with more complex attentional deployment (Kähkönen et al., 2001; Shelley et al., 1997). Together these findings indicate that dopamine is critically involved in later stages of selective attention.

Work with animal models indicates that striatal dopamine signals sharpen neuronal selectivity in the auditory cortex (Bao et al., 2001). Neurocomputational studies have also demonstrated that the dopaminergic tuning of the signal-to-noise ratio of information processing can affect the representational distinctiveness of representations in associative memory (Li, Lindenberger, \& Sikström, 2001; Li, Naveh-Benjamin, \& Lindenberger, 2005), working memory (Li \& Sikström, 2002), and perception (Li, von Oertzen, \& Lindenberger, 2006). In the present study, the performance of any $G$ carriers of the DARPP32 gene was primarily driven by the perceptual saliency of the syllables when processing competing auditory inputs, regardless of the task relevance of the information. Taken together, the available evidence suggests that striatal dopaminergic modulation of auditory processing affects the quality of perceptual representations (cf. findings for visual processing, Desimone \& Duncan, 1995; Reynolds \& Desimone, 2003). Less striatal dopamine modulation, as in animals processing auditory stimuli that were not coupled with the VTA stimulation (Bao et al., 2001 ), older adults (Passow et al., 2012a, in press), or, by analogy, in DARPP-32 any $\mathrm{G}$ carriers, may result in less distinctive representations of the competing auditory inputs in the auditory cortex, which add further demands for top-down attentional control. Furthermore, the observed DARPP-32 genotype effects are most likely not specific for the auditory domain. Instead, we think the genotype-based group differences may reflect the genotype effect on the functional interaction between frontal and striatal regions (e.g., Meyer-Lindenberg et al., 2007). We speculate that less striatal dopamine signaling, as shown by Bao et al. (2001) in animals without VTA stimulation during auditory processing, might lead to less distinctive representations that could add further demands for top-down attentional control. Future studies should investigate whether DARPP-32 genotype differences could also be found in an analog visual attentional control task.

\subsection{Genetic correlates of cortical evoked potentials}

The amplitude of early cortical evoked potentials, such as the $\mathrm{N} 1$ component, has been shown to be associated with attentional enhancement of early sensory selection of auditory inputs from the attended locations or channels (e.g., Hansen \& Hillyard, 1980; Hillyard et al., 1973) or inputs that appeared in the attended temporal intervals (e.g., Astheimer \& Sanders, 2009; Lange et al., 2003; Lange \& Röder,. 2006; Sanders \& Astheimer, 2008). The effects of attentional control incurred, for instance, by stimulus competition, stimulus-response conflict or error detection, are more commonly observed in an ERP modulation effect around 400-550 ms after stimulus onset (Frühholz et al., 2009; Larson et al., 2009; Liotti et al., 2000; Niedeggen \& Rösler, 1999; West \& Alain, 1999). Our findings suggest that the DARPP-32 gene is associated with the amplitude of these components. In comparison to any $G$ carriers, A homozygotes of the DARPP-32 gene showed larger N1 amplitude and N450 modulation effects. The genotype effect on the later N450 component was modulated by the extent of attentional-perceptual conflict, whereas the effect on the early N1 component was independent of this conflict. This is in line with earlier studies reporting that the effects of attentional 
demands are usually not observed in earlier cortical evoked potentials (i.e. the P3; Duncan-Johnson \& Kopell, 1981). Of particularly interest, our findings show that dopamine signaling modulates the early sensory selection process as reflected in $\mathrm{N} 1$ and the later conflict-related process as reflected in N450.

\subsection{Effects of dopamine genes on attentional aging}

It is well established that various aspects of dopaminergic modulation decline substantially during the course of usual aging (see Bäckman et al., 2000; Volkow et al., 1998; see Bäckman, Nyberg, Lindenberger, Li, \& Farde, 2006 for recent review). Using the same experimental paradigm, we recently have shown that older adults, relative to younger adults, are less able to focus their attention on the attended ear; rather, their performance is primarily driven by the perceptual saliency of the auditory inputs (Passow et al., 2012a). Relatedly, the N450 component as well as the conflict modulation effect of this component was not discernible in older adults (Passow et al., in press). In the present study, younger any G carriers of the DARPP-32 gene showed the N450 component, but a weaker conflict-related modulation of its amplitude. It would be of interest to examine potential interactions between the effects of normal aging and genetic predispositions (Lindenberger, Nagel, Chicherio, Li, Heekeren, \& Bäckman, 2008; Nagel et al., 2008) on the dopaminergic contributions to attentional control in future investigations.

\subsection{Conclusion}

The present findings suggest that genetic variation in the DARP32 gene, which affects the efficacy of striatal dopamine signaling, is associated with cortical evoked potentials reflecting early sensory selection and later conflict-related attentional control processes as well as with individual differences in attentional control over auditory perception. These findings corroborate the role of striatal dopamine in attention, and extend the effects of DARPP-32 gene to the attentional control of basic auditory perception. The DARPP-32 genotype effects on attentional control observed here are likely to interact with other dopamine-relevant genes as well as genes relevant for other transmitter systems, such as the cholinergic system (Espeseth, Endestad, Rootwelt, \& Reinvang, 2007). Interactions between dopamine and other transmitter systems need to be explored in future studies with larger samples.

\section{References}

Albert, K. A., Hemmings, H. C., Adamo, A. I. B., Potkin, S. G., Akbarian, S., Sandman, C. A., et al. (2002). Evidence for decreased DARPP-32 in the prefrontal cortex of patients with schizophrenia. Archives of General Psychiatry, 59(8), 705-712, http://dx.doi.org/10.1001/archpsyc.59.8.705.

Alexander, G. E., DeLong, M. R., \& Strick, P. L. (1986). Parallel organization of functionally segregated circuits linking basal ganglia to cortex. Annual Review of Neuroscience, 9, 357-381, http://dx.doi.org/10.1016/j.biopsych.2011.01.027.

Arnsten, A. F. T., \& Pilszka, S. R. (2011). Catecholamine influences on prefrontal cortical function: relevance to treatment of attention deficit/hyperactivity disorder and related disorders. Pharmacology Biochemistry and Behavior, 99, 211-216, http://dx.doi.org/10.1016/j.pbb.2011.01.02.

Astheimer, L. B., \& Sanders, L. D. (2009). Listeners modulate temporally selective attention during natural speech processing. Biological Psychology, 80(1), 23-34 http://dx.doi.org/10.1016/j.biopsycho.2008.01.015.

Bäckman, L., Ginovart, N., Dixon, R. A., Wahlin, T. B., Wahlin, A., Halldin, C., et al. (2000). Age-related cognitive deficits mediated by changes in the striatal dopamine system. American Journal of Psychiatry, 157, 635-637, http://dx.doi. org/10.1176/appi.ajp.157.4.635.

Bäckman, L., Nyberg, L., Lindenberger, U., Li, S. -C., \& Farde, L. (2006). The correlative triad among aging, dopamine, and cognition: current status and future prospects. Neuroscience and Biobehavioral Reviews, 30, 791-807, http://dx.doi. org/10.1016/j.neubiorev.2006.06.005.
Bao, S., Chan, V. T., \& Merzenich, M. M. (2001). Cortical remodeling induced by activity of vental tegmental dopamine neurons. Nature, 412, 79-83, http://dx. doi.org/10.1038/35083586.

Bayazit, O., Öniz, A., Hahn, C., Güntürkün, O., \& Özgören, M. (2009). Dichotic listening revisited: Trial-by-trial ERP analyses reveal intra- and inter-hemispheric differences. Neuropsychologia, 47(2), 536-545, http://dx.doi.org/10.1016/j. neuropsychologia.2008.10.002.

Bellgrove, M. A., Chambers, C. D., Johnson, K. A., Daibhis, A., Daly, M., Hawi, Z., et al. (2007). Dopaminergic genotype biases spatial attention in healthy children. Molecular Psychiatry, 12, 786-792, http://dx.doi.org/10.1038/sj.mp.4002022.

Brown, J. A., Emnett, R. J., White, C. R., Yuede, C. M., Conyers, S. B., O'Malley, K. L., et al. (2010). Reduced striatal dopamine underlies the attention system dysfunction in neurofibromatosis-1 mutant mice. Human Molecular Genetics, 19, 4515-4528, http://dx.doi.org/10.1093/hmg/ddq382.

Brown, V. J., \& Robbins, T. W. (1989). Elementary processes of response selection mediated by distinct regions of the striatum. Journal of Neuroscience, 9, 3760-3765.

Calabresi, P., Gubellini, P., Cantonze, D., Picconi, B., Bernardi, G., Chergui, K., et al (2000). Dopamine and camp-regulated phosphoprotein $32 \mathrm{kda}$ contrls both striatal long-term depression and long-term potentiation, opposing forms of synaptic plasticity. Journal of Neuroscience, 20, 8443-8451.

Carli, M., Evenden, J. L., \& Robbins, T. W. (1985). Depletion of unilateral striatal dopamine impairs initiation of contralateral action but not sensory attention. Nature, 313, 679-682, http://dx.doi.org/10.1038/313679a0.

Casey, B. J. (2005). Frontostriatal and frontocerebellar circuitry underlying cognitive control. In: U. Mayr, E. Awh, \& S. W. Keele (Eds.), Developing individuality in the human brain: A tribute to Michael I. Posner. Washington, DC: American Psychological Association pp. 141-166.

Casey, B. J., \& Durston, S. (2006). From behavior to cognition to the brain and back: What have we learned from functional imaging studies of attention deficit hyperactivity disorder? American Journal of Psychiatry, 163, 957-960, http://dx. doi.org/10.1176/appi.ajp.163.6.957.

Castellanos, F. X., Lee, P. P., Sharp, W., Jeffries, N. O., Greenstein, D. K., Clasen, L. S., et al. (2002). Developmental trajectories of brain volume abnormalities in children and adolescents with attention-deficit/hyperactivity disorder. Journal of the American Medical Association, 288, 1740-1748, http://dx.doi.org/10.1001/ jama.288.14.1740.

Ceponiene, R., Westerfield, M., Torki, M., \& Townsend, J. (2008). Modalityspecificity of sensory aging in vision and audition: Evidence from eventrelated potentials. Brain Research, 1215, 53-68, http://dx.doi.org/10.1016/j. brainres.2008.02.010.

Clark, V. P., \& Hillyard, S. A. (1996). Spatial selective attention affects early extrastriate but not striate components of the visual evoked potential. Journal of Cognitive Neuroscience, 8(5), 387-402, http://dx.doi.org/10.1162/ jocn.1996.8.5.387.

Colzato, L. S., Pratt, J., \& Hommel, B. (2010). Dopaminergic control of attentional flexibility: Inhibition of Return is associated with the dopamine transporter gene (DAT1). Frontiers in Human Neuroscience, 14(53), 1-6, http://dx.doi.org/ 10.3389/fnhum.2010.00053.

Colzato, L. S., Slagter, H. A., de Rover, M., \& Hommel, B. (2011). Dopamine and the management of attentional resources: Genetic marks of striatal D2 dopamine individual differences in the attentional blink. Journal of Cognitive Neuroscience, 23, 3576-3588, http://dx.doi.org/10.1162/jocn_a_00049.

Cools, R., Clark, L., \& Robbins, T. W. (2004). Differential responses in human striatum and prefrontal cortex to changes in object and rule relevance. Journal of Neuroscience, 24, 1129-1135, http://dx.doi.org/10.1523/JNEUROSCI.4312-03.2004.

Cools, R., Gibbs, S. E., Miyakawa, A., Jagust, W., \& D'Esposito, M. (2008). Working memory capacity in the human striatum. Journal of Neuroscience, 28, 1208-1212, http://dx.doi.org/10.1523/JNEUROSCI.4475-07.2008.

Crider, A., Blockel, L., \& Solomon, P. R. (1986). A selective attention deifict in the rat following induced dopamine receptor supersensitivity. Behavioral Neuroscience, $100,315-319$.

Curcic-Blake, B., Swart, M. Horst, G. T. J., Langers, D. R. :M. Kema, I. P. \& Aleman, A. (2012). Variation of the gene coding for DARPP-32 (PPP1R1B) and brain connectivity during associative emotional memory. NeuroImage, 59, 1540-1550, http://dx.doi.org/10.1016/j.neuroimage.2011.08.036.

Desimone, R., \& Duncan, J. (1995). Neural mechanisms of selective visual-attention. Annual Review of Neuroscience, 18, 193-222, http://dx.doi.org/10.1146/annurev. ne.18.030195.001205.

Doll, B. B., Hutchison, K. E., \& Frank, M. J. (2011). Dopaminergic genes predict individual differences in susceptibility to confirmation bias. Journal of Neuroscience, 31(16), 6188-6198, http://dx.doi.org/10.1523/jneurosci.6486-10.2011.

Duncan-Johnson, C. C. \& Kopell, B. S. (1981). The Stroop effect-Brain potentials localize the source of interference. Science, 214(4523), 938-940, http://dx.doi. org/10.1126/science.7302571.

Durstewitz, D., Seamans, J. K., \& Sejnowski, T. J. (2000). Dopamine-mediated stabilization of delay-period activity in a network model of prefrontal cortex. Journal of Neurophysiology, 83, 1733-1759.

Durston, S., Fossella, J. A., Casey, B. J., Hulshoff, P. H. E., Galvan, A., Schnack, H. G., et al. (2005). Differential effects of DRD4 and DAT1 genotypes on fronto-striatal gray matter volumes in a sample subjects with attention deficit hyperactivity disorder, their unaffected siblings, and controls. Molecular Psychiatry, 10, 678-685, http://dx.doi.org/10.1038/sj.mp.4001649.

Espeseth, T., Endestad, T., Rootwelt, H., \& Reinvang, I. (2007). Nicotine receptor gene CHRNA4 modulates early event-related potentials in auditory and visual oddball target detection tasks. Neuroscience, 147, 974-985, http://dx.doi.org/ 10.1016/j.neuroscience.2007.04.027. 
Fienberg, A. A., Hiroi, N., Mermelstein, P. G., Song, W. -J., Snyder, G. L., Nishi, A., et al. (1998). DARPP-32: Regulator of the efficacy of dopaminergic neurotransmission. Science, 281, 838-841, http://dx.doi.org/10.1126/science.281.5378.838.

Frank, M. J., Doll, B. B., Oas-Terpstra, J., \& Moreno, F. (2009). Prefrontal and striatal dopaminergic genes predict individual differences in exploration and exploitation. Nature Neuroscience, 12, 1062-1068, http://dx.doi.org/10.1038/nn.2342.

Frank, M. J., \& Fossella, J. A. (2011). Neurogenetics and pharmacology of learning, motivation, and cognition. Neuropsychopharmacology, 36, 133-152, http://dx. doi.org/10.1038/npp.2010.96

Frank, M. J., Loughry, B., \& O'Reilly, R. C. (2001). Interactions between frontal cortex and basal ganglia in working memory: A computational model. Cognitive Affective Behavioral Neuroscience, 1, 137-160, http://dx.doi.org/10.3758/ CABN.12.137.

Frühholz, S., Fehr, T., \& Herrmann, M. (2009). Early and late temporo-spatial effects of contextual interference during perception of facial affect. Internationa Journal of Psychophysiology, 74(1), 1-13, http://dx.doi.org/10.1016/j.ijpsycho. 2009.05.010.

Fusar-Poli, P., Rubia, K., Rossi, G., Sartori, G., \& Balottin, U. (2012). Striatal dopamine transporter alterations in ADHD: Pathophysiology or adaption to psychostimulants? A meta-analysis. American Journal of Psychiatry, 169, 264-272, http://dx. doi.org/10.1176/appi.ajp.2011.11060940.

Gorgoraptis, N., Mah, Y. H., Machner, B., Singh-Curry, V., Malhotra, P., Hadji-Michael, M., et al. (2012). The effects of the dopamine agonist rotigotine on hemispatial neglect following stroke. Brain, 135, 2478-2491, http://dx.doi.org/10.1093/ brain/aws154.

Gould, T. D., \& Manji, H. K. (2005). DARPP-32: a molecular switch at the nexus of reward pathway plasticity. Proceedings of National Academy of Sciences of the United States of America, 102, 253-352, http://dx.doi.org/10.1073/pnas. 0408700102.

Gratton, G., Coles, M. G. H., \& Donchin, E. (1983). A new method for off-line removal of ocular artefact. Electroencephalography and Clinical Neurophysiology, 55(4), 468-484, http://dx.doi.org/10.1016/0013-4694(83)90135-9.

Hämmerer, D., Biele, G., Müller, V., Thiele, H., Nürnberg, P., Heekeren, H. R., et al (2013). Effects of PPP1R1B (DARPP-32) polymorphism on feedback-related brain potentials across the lifespan. Frontiers in Psychology, 4, 1-8, http://dx. doi.org/10.3389/fpsyg.2013.00089 Article 89.

Hansen, J. C., \& Hillyard, S. A. (1980). Endogeneous brain potentials associated with selective auditory attention. Electroencephalography and Clinical Neurophysiology, 49(3-4), 277-290, http://dx.doi.org/10.1016/0013-4694(80)90222-9.

Hesse, S., Ballaschke, O., Barthel, H., \& Sabri, O. (2009). Dopamine transporter imaging in adult patients with attention-deficit/hyperactivity disorder. Psychiartiy Research: Neuroimaging, 171, 120-128, http://dx.doi.org/10.1016/j. pscychresns.2008.01.002.

Hillyard, S. A., Hink, R. F., Schwent, V. L., \& Picton, T. W. (1973). Electrical signs of selective attention in human brain. Science, 182(4108), 177-180, http://dx.doi. org/10.1126/science.182.4108.177.

Hiscock, M., \& Stewart, C. (1984). The effect of asymmetrically focused attention upon subsequent ear differences in dichotic listening. Neuropsychologia, 22(3), 337-351, http://dx.doi.org/10.1016/0028-3932(84)90080-0.

Hugdahl, K., \& Andersson, L. (1986). The forced-attention paradigm in dichotic listening to CV-syllables-A comparison between adults and children. Cortex, 22(3), 417-432.

Hugdahl, K., Rund, B. R., Lund, A., Asbjornsen, A., Egeland, J., Landro, N. I., et al. (2003). Attentional and executive dysfunctions in schizophrenia and depression: Evidence from dichotic listening performance. Biological Psychiatry, 53(7), 609-616, http://dx.doi.org/10.1016/S0006-3223(02)01598-6.

Jones, S. R., Gainetdinov, R. R., Jaber, M., Giros, B., Wightman, R. M., \& Caron, M. G. (1998). Profound neuronal plasticity in response to inactivation of the dopamine transporter. Proceedings of the National Academy of Sciences of the United States of America, 95(7), 4029-4034, http://dx.doi.org/10.1073/pnas.95.7.4029.

Kähkönen, S., Ahveninen, J., Jääskelainen, I. P., Kaakkola, S., Näätänen, R., Huttunen, J., et al. (2001). Effects of haloperidol on selective attention-A combined whole-head MEG and high-resolution EEG study. Neuropsychopharmacology, 25 (4), 498-504, http://dx.doi.org/10.1016/s0893-133x(01)00255-x.

Kanske, P., Plitschka, J., \& Kotz, S. A. (2011). Attentional orienting towards emotion: P2 and N400 ERP effects. Neuropsychologia, 49, 3121-3129, http://dx.doi.org/ 10.1016/j.neuropsychologia.2011.07.022.

Koepp, M. J., Gunn, R. N., Lawrence, A. D., Cunningham, V. J., Dagher, A., Jones, T., et al. (1998). Evidence for striatal dopamine release during a video game. Nature, 393, 266-268, http://dx.doi.org/10.1038/30498.

Kunii, Y., Ikemoto, K., Wada, A., Yang, Q. H., Kusakabe, T., Suzuki, T., et al. (2011) Detailed DARPP-32 expression profiles in postmortem brains from patients with schizophrenia: an immunohistochemical study. Medical Molecular Morphology, 44(4), 190-199, http://dx.doi.org/10.1007/s00795-010-0524-1.

Landau, S. M., Lal, R., O'Neil, J. P., Baker, S., \& Jagust, W. J. (2005). Striatal dopamine and working memory. Cerebral Cortex, 19, 445-454, http://dx.doi.org/10.1093/ cercor/bhn095.

Lange, K., \& Röder, B. (2006). Orienting attention to points in time improves stimulus processing both within and across modalities. Journal of Cognitive Neuroscience, 18, 715-729, http://dx.doi.org/10.1162/jocn.2006.18.5.715.

Lange, K., Rösler, F., \& Röder, B. (2003). Early processing stages are modulated when auditory stimuli are presented at an attentionded moment in time: an eventrelated potential study. Psychophysiology, 40, 806-817.

Larson, M. J., Kaufman, D. A. S., \& Perlstein, W. M. (2009). Neural time course of conflict adaptation effects on the Stroop task. Neuropsychologia, 47(3), 663-670, http://dx.doi.org/10.1016/j.neuropsychologia.2008.11.013.
Lewis, S. J. G., Dove, A., Robbins, T. W., Barker, R. A., \& Owen, A. M. (2003). Cognitive impairments in early Parkinson's disease are accompanied by reductions in activity in frontostriatal neural circuitry. Journal of Neuroscience, 23, 6351-6356.

Li, S. -C., Lindenberger, U., \& Sikström, S. (2001). Aging cognition: from neuromodulation to representation. Trends in Cognitive Sciences, 5, 479-486, http://dx. doi.org/10.1016/S1364-6613(00)01769-1.

Li, S. -C., Naveh-Benjamin, M., \& Lindenberger, U. (2005). Aging neuromodulation impairs associative binding: a neurocomputational account. Psychological Science, 16, 445-450, http://dx.doi.org/10.1111/j.0956-7976.2005.01555.x.

Li, S. -C., \& Sikström, S. (2002). Integrative neurocomputational perspectives on cognitive aging, neuromodulation, and representation. Neuroscience E Biobehavioral Reviews, 26, 795-808 doi: S0149763402000660.

Li, S. -C., von Oertzen, T. \& Lindenberger, U. (2006). A neurocomputational model of stochastic resonance and aging. Neurocomputing, 69, 1553-1560, http://dx.doi org/10.1016/j.neucom.2005.06.015.

Lindenberger, U., Nagel, I. E., Chicherio, C., Li, S. C., Heekeren, H. R., \& Bäckman, L. (2008). Age-related decline in brain resources modulates genetic effects on cognitive functioning. Frontiers in Neuroscience, 2, 234-244, http://dx.doi.org/ 10.3389/neuro.01.039.2008.

Liotti, M., Woldorff, M. G., Perez, R., \& Mayberg, H. S. (2000). An ERP study of the temporal course of the Stroop color-word interference effect. Neuropsychologia, 38(5), 701-711, http://dx.doi.org/10.1016/S0028-3932(99)00106-2.

Marshall, J. C., Caplan, D., \& Holmes, J. M. (1975). Measure of laterality. Neuropsychologia, 13(3), 315-321, http://dx.doi.org/10.1016/0028-3932(75)90008-1.

McNab, F., \& Klingberg, T. (2008). Prefrontal cortex and basal ganglia control access to working memory. Nature Neuroscience, 11, 103-107, http://dx.doi.org/ $10.1038 / \mathrm{nn} 2024$

Meyer-Lindenberg, A., Straub, R. E., Lipska, B. K., Verchinski, B. A., Goldberg, T., \& Callicott, J. H. (2007). Genetic evidence implicating DARPP-32 in human frontalstriatal structure, function, and cognition. Journal of Clinical Investigation, 117, 672-682, http://dx.doi.org/10.1172/JCI30413.

Nagano-Saito, A., Leyton, M., Monchi, O., Goldberg, Y. K., He, Y., \& Dagher, A. (2008) Dopamine depletion impairs frontostriatal functional connectivity during a setshifting task. Journal of Neuroscience, 28(14), 3697-3706, http://dx.doi.org/ 10.1523/jneurosci.3921-07.2008

Nagel, I. E., Chicherio, C., Li, S. -C., von Oertzen, T., Sander, T., Villringer, A., et al. (2008). Human aging magenifies genetic effects on executive functioning and working memory. Frontiers in Human Neuroscience, 2, 1-8, http://dx.doi.org 10.3389/neuro.09.001.2008 Article no. 1.

Narita, M., Matsushima, Y., Niikura, K., Narita, M., Takagi, S., Nakahara, K., et al. (2010). Implication of dopaminergic projection from the ventral tegmental area to the anterior cingulate cortex in mu-opioid-induced place preference. Addiction Biology, 15(4), 434-447, http://dx.doi.org/10.1111/j.1369-1600.2010.00249.x.

Niedeggen, M., \& Rösler, F. (1999). N400 effect reflect activation spread during retrieval of arithmetic facts. Psychological Science, 10, 271-276, http://dx.doi. org/10.1111/1467-9280.00149.

Nishi, A., Snyder, G. L., \& Greengard, P. (1997). Bidirectional regulation of DARPP-32 phosphorylation by dopamine. Journal of Neuroscience, 17, 8147-8155.

Oldfield, R. C. (1971). Assessment and analysis of handedness-Edinburgh Inventory. Neuropsychologia, 9(1), 97, http://dx.doi.org/10.1016/0028-3932(71) 90067-4.

Passow, S., Westerhausen, R., Wartenburger, I., Hugdahl, K., Heekeren, H. R., Lindenberger, U., et al. (2012). Human aging compromises attentional control of auditory perception. Psychology and Aging, 27, 99-105, http://dx.doi.org/ 10.1037/a0025667.

Passow, S., Westerhausen, R., Hugdahl, K., Wartenburger, I., Heekeren, H.R., Lindenberger, U., et al., Electrophysiological correlates of adult age differences in attentional control of auditory processing, Cerebral Cortex. http://dx.doi.org/ $10.1093 /$ cercor/bhs306, in press.

Pennartz, C. M. A., Berke, J. D., Graybiel, A. M., Ito, R., Lansink, C. S., van der Meer, M. et al. (2009). Corticostriatal interactions during learning, memory processing, and decision making. Journal of Neuroscience, 29(41), 12831-12838, http://dx doi.org/10.1523/jneurosci.3177-09.2009.

Phillips, A. G., Ahn, S., \& Floresco, S. B. (2004). Magnitude of dopamine release in medial prefrontal cortex predicts accuracy of memory on a delayed response task. Journal of Neuroscience, 24, 547-553, http://dx.doi.org/10.1523/JNEUROSCI. 4653-03.2004.

Reynolds, J. H., \& Desimone, R. (2003). Interacting roles of attention and visual salience in V4. Neuron, 37, 853-863, http://dx.doi.org/10.1016/S0896-6273(03) 00097-7.

Ryan, T. S. (1959a). Multiple comparisons in psychological research. Psychological Bulletin, 56, 26-47, http://dx.doi.org/10.1037/h0042478.

Ryan, T. S. (1959b). Comments on orthogonal components. Psychological Bulletin, 56 394-396, http://dx.doi.org/10.1037/h0041280.

Sanders, L. D., \& Astheimer, L. B. (2008). Temporally selective attention modulates early perceptual processing: event-related potential evidence. Perception and Psychophysics, 70, 732-742, http://dx.doi.org/10.3758/PP.70.4.732.

Schirmer, A., \& Kotz, S. A. (2003). ERP evidence for a sex-specific stroop effect in emotional speech. Journal of Cognitive Neuroscience, 15, 1135-1148.

Seamans, J. K., \& Yang, C. R. (2004). The principal features and mechanisms of dopamine modulation in the prefrontal cortex. Progress in Neurobiology, 74, 1-57, http://dx.doi.org/10.1016/j.pneurobio.2004.05.006.

Shelley, A. M., Catts, S. V., Ward, P. B., Andrews, S., Mitchell, P., Michie, P., et al (1997). The effect of decreased catecholamine transmission on ERP indices of selective attention. Neuropsychopharmacology, 16(3), 202-210, http://dx.doi. org/10.1016/s0893-133x(96)00190-x. 
Shumay, E., Folwer, J. S., \& Volkow, N. D. (2010). Genomic features of the human dopamine transporter gene and its potential epigenetic states: Implications for phenotypic diversity. PLoS One, 5, e11067, http://dx.doi.org/10.1371/journal. pone.0011067.

Siessmeier, T., Kienast, T., Wrase, J., Larsen, J., Smolka, M. N., Heinz, A., et al. (2006) Net influx of plasma 6-[18F] fluoro-l-DOPA (FDOPA) to the ventral striatum correlates with prefrontal processing of affective stimuli. European Journal of Neuroscience, 24, 305-313, http://dx.doi.org/10.1111/j.1460-9568.2006.04903.x.

Svenningsson, P., Nishi, A., Fisone, G., Girault, J. -A., Nairn, A. C., \& Greengard, P. (2004). DARPP-32: An integrator of neurotransmission. Annual Review of Pharmacology and Toxicology, 44, 269-296.

Swanson, J. M., Kinsbourne, M., Nigg, J., Lanphear, B., Stefanatos, G. A., Volkow, N., et al. (2007). Etiologic subtypes of attention-deficit/hyperactivity disorder: brain imaging, molecular genetic and environmental factors and the dopamine hypothesis. Neuropsychology Review, 17, 39-59, http://dx.doi.org/10.1007/ s11065-007-9019-9.

Vernaleken, I., Buchholz, H. -G., Kumakura, Y., Siessmeier, T., Stoeter, P., Bartenstein, P., et al. (2007). Prefrontal cognitive performance of healthy subjects prositively correlates with cerebral FDOPA influx: An exploratory $\left[{ }^{18} \mathrm{~F}\right]-$ fluoro-L-DOPA-PET investigation. Human Brain Mapping, 28, 931-939, http://dx.doi.org/10.1002/ hbm.20325.

Vijyayraghavan, S., Wang, M., Birnbaum, S. G., Shari, G., Williams, G. V., \& Arnsten, A. F. T. (2007). Inverted-U dopamine receptor actions on prefrontal neurons engaged in working memory. Nature Neuroscience, 10, 376-384, http://dx.doi. org/10.1038/nn1846.

Volkow, N. D., Wang, G. -J., Folwer, J. S., Ding, Y. S., Gur, R. C., Gatley, J., et al. (1998), Parallel loss of presynaptic and postsynaptic dopamine markers in normal aging. Annals of Neurology, 44, 143-147, http://dx.doi.org/10.1002/ana. 410440125.

Volkow, N. D., Wang, G. -J., Newcorn, J., Fowler, J. S., Telang, F., Solanto, M. V., et al. (2007). Brain dopamine transporter levels in treatment and drug naïve adults with ADHD. NeuroImage, 34, 1182-1190, http://dx.doi.org/10.1016/j.neuroimage. 2006.10.014.

Ward, N. M., \& Brown, V. J. (1996). Covert orienting of attention in the rat and the role of striatal dopamine. Journal of Neuroscience, 16, 3082-3088.

West, R., \& Alain, C. (1999). Event-related neural activity associated with the Stroop task. Cognitive Brain Research, 8(2), 157-164, http://dx.doi.org/10.1016/S09266410(99)00017-8.

Westerhausen, R., Moosmann, M., Alho, K., Belsby, S., Hämäläinen, H., Medvedev, S., et al. (2010). Identification of attention and cognitive control networks in a parametric auditory fMRI study. Neuropsychologia, 48(7), 2075-2081, http://dx. doi.org/10.1016/j.neuropsychologia.2010.03.028.

Wilcox, R. R. (1987). New designs in analyses of variance. Annual Reviews of Psychology, 38, 29-60, http://dx.doi.org/10.1146/annurev.ps.38.020187.000333.

Williams, S. M., \& Goldman-Rakic, P. S. (1998). Widespread of origin of the primate mesofrontal dopamine system. Cerebral Cortex, 8, 321-345, http://dx.doi.org/ $10.1093 /$ cercor/8.4.321 